This is the final peer-reviewed accepted manuscript of:

Dino Bindi, Fabrice Cotton, Daniele Spallarossa, Matteo Picozzi, Eleonora Rivalta; Temporal Variability of Ground Shaking and Stress Drop in Central Italy: A Hint for Fault Healing?. Bulletin of the Seismological Society of America 2018; 108 (4): 18531863.

The final published version is available online at: https://doi.org/10.1785/0120180078

Rights / License:

The terms and conditions for the reuse of this version of the manuscript are specified in the publishing policy. For all terms of use and more information see the publisher's website.

This item was downloaded from IRIS Università di Bologna (https://cris.unibo.it/)

When citing, please refer to the published version. 
1 Temporal variability of ground-shaking and stress

$2 \quad$ drop in central Italy: a hint for fault healing?

D. Bindi(1), F. Cotton(1,2), D. Spallarossa(3),

M. Picozzi(4), and E. Rivalta(1)

(1) German Research Centre for Geosciences GFZ, Potsdam, Germany;

(2) also at University of Potsdam, Potsdam, Germany

(3) University of Genova, DISTAV, Genova, Italy;

(4) University Federico II, Napoli, Italy;

4

June 1, 2018

5

- Dino Bindi, German Research Centre for Geosciences GFZ, Telegrafen-

7 berg, Helmholtzstrasse 6, 14467 Potsdam, Germany; bindi@gfz-potsdam.de

8

- Fabrice Cotton, German Research Centre for Geosciences GFZ, Tele-

9 grafenberg, Helmholtzstrasse 6, 14467 Potsdam, Germany; fcotton@gfz-

$10 \quad$ potsdam.de

11

- Daniele Spallarossa, University of Genova, DISTAV, Viale Benedetto

12

XV 5, 16132 Genova, Italy; daniele@dipteris.unige.it 
- Matteo Picozzi, University Federico II, Via Cintia, 80126 Napoli, Italy; matteo.picozzi@unina.it

- Eleonora Rivalta, German Research Centre for Geosciences GFZ, Telegrafenberg, Helmholtzstrasse 6, 14467 Potsdam, Germany; rivalta@gfzpotsdam.de

\section{Abstract}

Ground Motion Prediction Equations (GMPEs) are calibrated to predict the intensity of ground shaking at any given location, based on earthquake magnitude, source-to-site distance, local soil amplifications and other parameters. GMPEs are generally assumed to be independent of time; however, evidence is increasing that large earthquakes modify the shallow soil conditions and those of the fault zone for months or years. These changes may affect the intensity of shaking and result in time-dependent effects that can potentially be resolved analyzing between-event residuals (residuals between observed and predicted ground motion for individual earthquakes averaged over all stations). Here we analyze a data set of about 65000 recordings for about 1400 earthquakes in the moment magnitude range 2.5-6.5 occurred in central Italy from 2008 to 2017 to capture the temporal variability of the ground shaking at high frequency. We first compute for each earthquake between-event residuals in the Fourier domain with respect to a ground motion prediction equation developed ad-hoc for the analyzed data set. The between-events show large changes after the occurrence of mainshocks such as the Mw 6.3, 2009 L' Aquila, the 2016, Mw 6.2 Amatrice and Mw 6.5 
36 Norcia earthquakes. Within the time span of a few months after the main-

37 shocks, the between-event contribution to the ground shaking varies by a

38 factor 7 . In particular, we find a large drop in the between-events in the

39 aftermath of the l'Aquila earthquake, followed by a slow positive trend that

40 leads to a recovery interrupted by a new drop at the beginning of 2014 .

${ }_{41}$ We also quantify the frequency-dependent correlation between the Brune

42 stress-drop $\Delta \sigma$ and the between-events. We find that the temporal changes

43 of $\Delta \sigma$ resemble those of the between-event residuals; in particular, during

44 the period when the between-events show the positive trend, the average

45 logarithm of $\Delta \sigma$ increases with an annual rate of 0.19 (i.e., the amplifica-

46 tion factor for $\Delta \sigma$ is 1.56 per year). Breakpoint analysis located a change in

47 the linear trend coefficients of $\Delta \sigma$ versus time in February 2014 although no

48 large earthquakes occurred at that time. Finally, the temporal variability

49 of $\Delta \sigma$ mirrors the relative seismic velocity variations observed in previous

50 studies for the same area and period, suggesting that both crack-healing

51 along the main fault system and healing of micro-cracks distributed at shal-

52 low depths throughout the surrounding region might be necessary to explain

53 the wider observations of post-earthquake recovery.

\section{${ }_{54}$ Introduction}

55 The intensity of seismic shaking at a given site is a function of the earthquake 56 size, style of faulting, source-to-site distance and site condition. Ground 57 motion prediction equations (GMPEs) incorporate these functional depen58 dencies and are time-independent, meaning that the intensity of shaking is 
assumed to be independent of any process affecting the fault zone. However, some observations suggest that shaking intensity changes depending on the timing of earthquakes within sequences. For example, it has been observed that aftershocks generate lower median ground motion in the high frequencies (e.g., Boore and Atkinson 1989) and, therefore, they have been flagged in the recent NGA-West2 strong motion data set (Wooddell and Abrahamson, 2014) allowing GMPE developers to treat them differently from mainshocks. Some of the variability in the observed shaking may be explained by variability in the stress drop (e.g., Wu and Chapman, 2017). Analyzing the NGA-West2 data, Baltay and Hanks (2014) found that average stress drop for mainshocks is $30 \%$ larger than the average stress drop for aftershocks.

Identifying repeating deviations from the medial model can help distinguish processes that are not modeled but contribute significantly to ground motion variability. For example, several studies correlated earthquake-specific residuals (also called between-event or inter-event) to stress drop variability (e.g., Anderson and Lei, 1994; Bindi et al., 2007; Cotton et al., 2013; Oth et al., 2017; Bindi et al., 2017; Baltay et al., 2017; Ameri et al., 2017; Trugman and Shearer, 2018). Therefore, presence of any temporal pattern in the distribution of residuals can be used as diagnostic of time-dependent fault or medium properties, and ultimately help understanding how non-stationary processes, such as protracted seismic sequences or the long precursory phase of large earthquakes, affect ground motion. For example, Socquet et al (2016) and Piña-Valdés et al. (2018), in discussing the ground-shaking time-dependencies observed during the 2014 Iquique subduction sequence, 
suggested that the temporal changes in the between-event residuals were associated with aseismic slip around the rupture area.

Here we take advantage of a large data set from central Italy to investigate the temporal changes of the between-event residuals and their link with the stress drop $\Delta \sigma$ variability. The data set includes about 1400 earthquakes in the magnitude range 2.5-6.5, belonging to the main sequences of the last ten years, i.e. the 2009 L'Aquila (Chiaraluce et al., 2011) and the 2016-17 Amatrice-Visso-Norcia (Chiaraluce et al., 2017) sequences. About 60 earthquakes occurred in area of the 2013-14 Gubbio swarm (De Gori et al., 2015) are included as well. We first calibrate an ad-hoc GMPE for the Fourier amplitude spectra and we evaluate the between-event residuals at different frequencies. Then, the between-event are used as exploratory tool to detect event-dependent temporal changes in the ground shaking and we conclude presenting the temporal variability of $\Delta \sigma$.

\section{Data}

In this study, we analyze about 65000 recordings (for each component of motion) from 1400 earthquakes recorded by 340 stations installed in Central Italy (Figure 1 and Figure S1 of the electronic supplements to this article). The earthquakes cover the magnitude range from 2.5 to 6.5 and hypocentral distances from 10 to $180 \mathrm{~km}$ are considered. The data set includes the main sequences occurred in the area in the last 10 years, namely the $2009, \mathrm{Mw}$ 6.3 L'Aquila (indicated as $e_{1}$ in Figure 1); the 2016, Mw 6.1 Amatrice $\left(e_{2}\right.$ in Figure 1); the $2016 \mathrm{Mw}$ 6.1, Visso ( $e_{4}$ in Figure 1); the 2016, Mw 6.5, 
Norcia ( $e_{3}$ in Figure 1) (for a map with the time evolution of the events, see Figure S2 in the electronic supplements to this article). Following Bindi et al. (2018), in this study we consider the moment magnitude from the Geofon catalog for all events with $\mathrm{Mw} \geq 5.7$ but the 2009, L'Aquila mainshock, for which we use the Global Centroid Moment Tensor (GCMT) value since the Geofon solution is not available (see the Data and Resources section). The data set also includes recordings from 59 earthquakes with magnitude larger than 2.5 occurred in the area of the 2013-14 Gubbio swarm; a complete description of the swarm is given by De Gori et al. (2015) and Valoroso et al. (2017). The station distribution is shown in Figure S1 in the electronic supplement to this article.

We analyse the Fourier amplitude spectra (FAS) of S-waves windows band-pass filtered with a variable high pass corner frequency depending on the signal-to-noise ratio. The Butterworth high-pass corner varies in the range $0.05-0.4 \mathrm{~Hz}$ while the low pass one was fixed to $40 \mathrm{~Hz}$. The FAS are smoothed using the Konno and Ohmachi (1998) algorithm (the smoothing parameter b was set to 40). Details about the data selection and processing are provided by Pacor et al. (2016) and by Bindi et al. (2017).

\section{Source parameters}

For each earthquake, we consider the source parameter (i.e., stress drop and seismic moment) derived by Bindi et al. (2017) using a generalized inversion technique (GIT). In the GIT approach (e.g., Castro et al., 1990; Oth et al., 2011), the spectral values of a set of earthquakes recorded by a network of 
stations are simultaneously inverted to isolate the contribution of source, propagation and site effects. The GIT approach exploits the redundancy of information (that is, the same earthquake is recorded at several stations located at different distances, and several earthquakes are recorded at the same station) to set-up an over-determined system of equations solved in a least-squares sense. To remove unresolved degrees of freedom which generate trade-offs among different components of the solution, some constraints are applied, such as the choice of a reference distance at which the attenuation is assumed to be one and a reference site condition (i.e., one or more stations whose site amplification is assumed to be known). In this study, we use the results of Bindi et al (2018) who applied a non-parametric GIT inversion where any a-priori seismological models for source and attenuation were adopted during the GIT inversion. To estimate the seismic moment and the corner frequency for each earthquake, the resulting non-parametric source spectra were fit to a Brune (1970) source model which assumes a circular fault with uniform stress drop. In Bindi et al. (2018), the source fit was performed allowing a deviation of the high frequency acceleration spectral level from a constant value as predicted by the Brune model. The highfrequency slope of the source spectrum is referred to as $k_{\text {source }}$. Given the seismic moment and the corner frequency, the stress drop was computed following Eshelby (1957) and Keilis-Borok (1959).

The source parameters are shown in Figure 2, in terms of scaling between $\Delta \sigma, \mathrm{Mw}$ and hypocentral depth. Most of the considered depths including those of the mainshocks are located between 5 and $10 \mathrm{~km}$. The stress drop tends to increase with depth and has a strong magnitude dependence (Pacor 
et al., 2016; Bindi et al. 2017). The mainshocks have the largest $\Delta \sigma$, around $10 \mathrm{MPa}$. The overall $\Delta \sigma$ variability covers almost three orders of magnitude. The procedure followed in this study to estimate the uncertainties on $\Delta \sigma$ is described in the electronic supplement to this article.

\section{Ground motion model}

In this study, we describe the Fourier amplitude spectra $F A S(f, R)$ at frequency $f$ of S-waves recorded at hypocentral distance $R$ with the following seismological model:

$$
F A S(f, R)=S(f) \cdot P(f, R) \cdot Z(f)=K \frac{M_{0} f^{2}}{1+\left(\frac{f}{f_{c}}\right)^{2}} \cdot \frac{1}{R^{n}} \exp \left(-\frac{\pi f R}{Q \beta}\right) \cdot Z(f)
$$

where the acceleration source spectra $S(f)$ is parametrized considering an $\omega$-square model (Aki, 1967) and the spectral attenuation with distance $P(f, R)$ is controlled by the geometrical spreading exponent $n$ and the anelastic attenuation, the latter being modeled through the quality factor $Q(f)$. In equation 1 , the constant $K$ depends on the density and velocity at the source location, on radiation pattern and free surface amplification effects, whereas $Z(f)$ accounts for site amplification effects. We only consider far-field source terms and extended-source effects are not accounted for. The asymptotic form of the source spectrum is as follow: 


$$
S(f) \propto \begin{cases}M_{0} f_{c}^{2} & \text { if } f \gg f_{c} \\ M_{0} f^{2} & \text { if } f \ll f_{c}\end{cases}
$$

172 The source spectrum depends on two parameters, the seismic moment 173 $M_{0}$ and the corner frequency $f_{c}$ connected through the stress drop $\Delta \sigma$ 174 (Brune, 1970; Eshelby, 1957) as follows:

$$
\Delta \sigma \propto M_{0} d^{-3} \propto M_{0} f_{c}^{3}
$$

175 where $d$ is the source radius. Considering equation 3, equation 2 can be 176 re-written as:

$$
S(f) \propto \begin{cases}M_{0}^{\frac{1}{3}} \Delta \sigma^{\frac{2}{3}} & \text { if } f \gg f_{c} \\ M_{0} f^{2} & \text { if } f \ll f_{c}\end{cases}
$$

177 If the average stress drop of the analyzed earthquakes is assumed to 178 be constant, the scaling of the source spectrum with the earthquake size is 179 controlled only by the seismic moment (Aki, 1967). Under this assumption and considering a mixed effect regression (Bates et al., 2015), Equations 1 and 4 suggest the following parametric model for $F A S(f, R)$ :

$$
\ln (F A S)=a_{1}+a_{2} M w+a_{3} \ln (R)+a_{4} R+\delta B_{e}+\delta B_{s}+\epsilon
$$

where the moment magnitude $\mathrm{Mw}$ is proportional to $\log \left(M_{0}\right)$ (Hanks and Kanamori, 1979). In equation 5 , the coefficients $a_{i}$ are the (frequency dependent) fixed effects which define the median prediction; $\delta B_{e}, \delta B_{s}$ are the 
random effects for the earthquake and station grouping levels, respectively; $\epsilon$ is the residual distribution. In order to allow more complex scaling with magnitude, the functional form considered in this study is the following:

$$
\begin{aligned}
& \ln (F A S)=e_{1}+b_{1}\left(M w-M_{r e f}\right)+b_{2}\left(M-M_{r e f}\right)^{2}+ \\
& {\left[c_{1}+c_{2}\left(M-M_{r e f}\right)\right] \ln \left(\frac{R}{R_{r e f}}\right)+c_{3}\left(R-R_{r e f}\right)+\delta B_{e}+\delta B_{s}+\epsilon}
\end{aligned}
$$

with $M_{r e f}=3.5$ and $R_{\text {ref }}=1 \mathrm{~km}$. In equation (6), the fixed effect coefficients describe the scaling with distance $\left(c_{1}\right.$ and $c_{3}$ are connected to the geometrical spreading attenuation and the quality factor, respectively) and with magnitude $\left(b_{1}\right.$ and $b_{2}$ are controlling the scaling with the seismic moment). Coefficient $c_{2}$ introduces a magnitude dependency in the attenuation with distance, while the off-set $e_{1}$ depends (at high frequency) on source characteristics such as the average stress drop, among other quantities. The between-event $\delta B_{e}$ quantifies the systematic deviation of recordings for the same event with respect the median prediction. At high frequencies, the deviation of the stress drop of any earthquakes from the average of the population is expected to contribute to the $\delta B_{e}$ residuals while differences in the average radiation pattern among the earthquakes due to uneven station distribution can contribute to $\delta B_{e}$ at low frequency (along with other factors such as differences in the density and velocity at the source location, errors in the magnitude values, etc). The between station $\delta B_{s}$ random effects, sometimes referred to as $\delta S 2 S$, absorb the frequency dependent site amplification indicated with $Z(f)$ in equation 1 .

The frequency-dependent coefficients of the model (6) and the standard 
deviations of $\delta B_{e}, \delta B_{s}$, and $\epsilon$ are listed in Table S1 of the electronic supplement to this article. The residuals $\epsilon$ versus hypocentral distance and $\delta B e$ versus magnitude are exemplified in Figure 3 for two frequencies. Over the intervals well constrained by data, the average residuals do not show systematic trends with the predictor variables but the variability of $\delta B_{e}$ increases with frequency (see also Table S1). Weak trends at short distances (at high frequency) and for large magnitude (at low frequencies), which are not impacting on the analysis performed in this study, could be removed by introducing distance and magnitude hinges in equation (5).

\section{Between-event temporal variability}

The temporal trend of the between-event $\delta B_{e}$ at $10 \mathrm{~Hz}$ is shown in Figure 4 while zooms over different time windows are presented in Figure S3 of the electronic supplement to this article. In addition to the large variability in the aftermath of the mainshock occurrence, the most striking feature in Figure 4 is the positive trend developing from the end of 2009, a few months later than the April 6, 2009 L'Aquila mainshock, to late 2013-early 2014. In the period from early 2014 to August 2016, when the Amatrice sequence started, $\delta B_{e}$ shows a large variability with average value close to zero. When observed at low frequencies (Figure 4$), \delta B_{e}$ shows a weak trend with time. As discussed in the model development section, $\delta B_{e}$ is expected to absorb, at high frequencies, the effect of the stress drop variability. Figure 5 shows that the correlation between $\delta B_{e}$ and $\Delta \sigma$ is significant at $10 \mathrm{~Hz}$, whereas the correlation is low at $0.75 \mathrm{~Hz}$. It is worth noting that the mainshocks and the 
largest aftershocks deviate from the average correlation trend defined by the aftershock population. We ascribe this behavior to the fact that while $\Delta \sigma$ varies over three order of magnitude for small events, it is almost constant for earthquakes above magnitude 5. Since GMPE well describe the average the ground shaking generated by the largest magnitudes, their $\delta B_{e}$ are distributed close to zero (Figure 3). The correlation of $\delta B_{e}$ with $\Delta \sigma$ is also highlighted in Figure S4 of the electronic supplement where large positive residuals are associated to events with $\Delta \sigma$ higher than $0.6 \mathrm{MPa}$ (i.e., the population average; Bindi et al., 2018) while earthquakes with lower stress drop have negative residuals. Figure 5 also shows the dependence of $\delta B_{e}$ on hypocentral depth. The observed trend is reflecting the $\Delta \sigma$ dependences on depth as shown in Figure 2. The degree of correlation measured in terms of Pearson coefficient (Figure 6) confirms that the correlation is strongest around $10 \mathrm{~Hz}$. The decrease of correlation toward low frequencies reflects the diminishing importance of $\Delta \sigma$ in determining the spectral amplitudes at frequencies lower than the corner one while the reduction above $10 \mathrm{~Hz}$ suggests that source-related effects other than the stress drop also affect the ground motion variability at high frequencies. The high frequencies radiations depends on many factors: small scale slip heterogeneity/slip roughness (Causse et al., 2010), rupture velocity and slip source function (Mai et al., 2017) and near source attenuation (Purvance and Anderson, 2003). For example, analyzing a smaller data set, Bindi et al. (2017) found a correlation between $\delta B_{e}$ and the slope at high frequency of the acceleration source spectrum. 
 \\ Stress drop temporal variability}

The stress-drop variability with time (Figure 7a) resembles the variability observed for $\delta B_{e}$. If the earthquakes are grouped according to the latitude of their epicenters as shown in Figure 1, and focusing on the average trend, we observe that:

- $\Delta \sigma$ of earthquakes located in the L'Aquila region (Figure 7b) rapidly diminishes during the first month after the mainshock on April 6; the recovery starts after about two months (see also Figure 8a);

- for events located in the Campotosto segment (Chiaraluce et al., 2011) (Figure $7 \mathrm{c}$ ), the recovery of the logarithm of $\Delta \sigma$ develops over a time span of 4 years, from 2010 to 2013, at an annual rate of 0.17 (i.e., the amplification factor for $\Delta \sigma$ is 1.5 per year). We recall that the Campotosto segment includes the northernmost termination of the 2009 sequence and the southern tip of the 2016 fault system (Chiaraluce et al., 2017). In particular, the four events with magnitude larger than 5 occurred in January 2017 are characterized by large $\Delta \sigma$ (see Figure 8), as for the largest aftershocks occurred over this segment during the 2009 sequence.

- a decrease in $\Delta \sigma$ is observed at the beginning of 2014, although no large earthquakes occurred at that time. Figure 9 shows the results of a breakpoint analysis (Bai, 1994; Zeileis et al., 2002; 2003) performed to detect changes in the coefficients of the linear regression with time. The analysis identifies a change-point within the period February 10 - 
March 8, 2014 across which the slope of the logarithm of $\Delta \sigma$ with time reduce from $4.7 e^{-04}$ to $9.4 e^{-05}$ (the amplification factor per year for $\Delta \sigma$ reduces from 1.5 to 1 ). A detailed description of the breakpoint analysis is reported in the electronic supplement to this article. The cause driving this drop are not known. No large earthquakes occurred in the area around February-March 2014; the only notable event is the Gubbio swarm (Gualandi et al., 2017). At this stage, it is difficult to assess the plausibility of its involvement in the process we are examining here. Possible connections with the seismic and aseismic moment released during the 2013-14 Gubbio swarm are worth to be the subject of future work.

- earthquakes located in the northern group (Figure 7d) mainly belong to the 2016-17 Amatrice-Norcia-Visso sequence (Chiaraluce et al., 2017); also for these events, $\Delta \sigma$ is larger for the mainshocks and for the aftershocks above magnitude 5.5 (Figure S5 in the electronic supplement), and decreases after the mainshock occurrence (Figure 8c). The events occurred in this area before the 2016-17 sequence follow the same trends observed for the Campotosto segment.

\section{Discussions and conclusions}

The between-event residuals $\delta B_{e}$ computed for ten years of data in central Italy show significant temporal variability at high frequency (Figure 4). On one hand, the time dependency of $\delta B_{e}$ imply temporal changes of the ground shaking that could have an impact over the short term hazard. In the first 
couple of months, $\delta B_{e}$ at $10 \mathrm{~Hz}$ varies in the range from -1 to 1 , roughly (i.e., about a factor 0.7 for spectral amplitudes); after a couple of months from L' Aquila mainshock, a trend develops with $\delta B_{e}$ increasing on average from about 0 to 0.8 , (i.e., about factor 2 in high frequency spectral content). On the other hand, Figure 7 shows that the high-frequency between-events variability resembles the time variability of the stress drop $\Delta \sigma$. Temporal variability of $\Delta \sigma$ has been observed in previous studies. For example, Abercrombie (2014) analyzed 25 earthquakes in three repeating sequences on the San Andreas at Parkfield, observing a long term gradual increase of $\Delta \sigma$ before the 2004 magnitude 6 earthquake. The values show an immediate decrease after the mainshock occurrence before recovering to previous values. Using a long-term stress drop catalog, Chen and Shearer (2013) found relatively stable long-term average stress drop in Southern California but a slow increase trend after large main shocks within the Landers fault zone was also identified, in agreement with a possible long-term fault zone recovery (Li et al., 1998).

Fault healing has been shown to promote the generation of high-frequency earthquakes both in laboratory experiments and on natural faults (e.g., Marone, 1998; McLaskey et al., 2012, Scuderi et al., 2016). The connection between pore pressure and effective normal stress has been also advocated to explain the time variability of the stress strop. Recently, Yoshida et al. (2017) analyzed a swarm triggered by the 2011 Tohoku earthquake, evaluating temporal changes in stress drop and b-value. They discussed the temporal variations of stress drop (very similar patterns to those observed in this study) in terms of changes in the frictional strength due to fluid 
migration. In central Italy, pore pressure diffusion due to fluids migration played a role in the preparatory phase of the L'Aquila mainshock (e.g., Di Luccio et al 2010). However, pore pressure diffusion generally occurs over time scales of weeks to months. Thus, we reckon it is difficult to attribute solely to migration of fluids or pore pressure the variations we observe, which occur over time scales of several years.

Among other techniques, monitoring changes in seismic velocities has been shown to be effective in detecting fault healing and reloading processes (e.g., Brenguier et al., 2008; Chen et al., 2010). For example, Peng and Ben-Zion (2006) investigated the temporal variations of seismic velocity along the north Anatolian fault analyzing repeating earthquake clusters in the aftershock zones of the 1999 Izmit and Düzce earthquakes. The authors observed a sharp seismic velocity reduction immediately after the Düzce main shock, followed by a gradual logarithmic-type recovery. They concluded that the temporal changes of material properties occur in the topmost portion of the crust and, although the change is more prominent at stations located close to recently ruptured fault zones, it is not limited to the immediate vicinity of the fault zone. In central Italy, Soldati et al (2015) computed the relative velocity variation from cross-correlations of noise data over the period 2008-2012, including the 2009 L'Aquila main shock. The temporal variation obtained for the relative velocity (reproduced in Figure 10) has a trend very similar to the stress drop: an abrupt co-seismic decrease at the time of the main shock occurrence, followed by an unstable behavior for a few months and, finally, a recovery of the velocity (see also in Figure 7c). Regarding the spatial distribution of the co-seismic velocity drop, Soldati 
et al. (2015) compared the velocities changes averaged over a one-month time window selected before and after the main shock occurrence, and excluding the day of the main shock. They found (see their Figure 5) that the drop was maximum over the area surrounding the L'Aquila epicentre and in the northeast direction from the fault zone, including the Campotosto area. The similarities of the trends observed for the stress drop and for the relative velocity variations suggest that, in agreement with Heckels et al (2018), the recovery can be associated both to crack-healing along the main fault system and to healing of micro-cracks distributed at shallow depths throughout the surrounding region.

\section{Data and Resources}

The R software (R Development Core Team, 2008; http://www.R-project.org) has been used in this study to perform the regressions. In particular, the packages lme4 (Bates et al., 2015; https://cran.r-project.org/web/ packages/lme4/news.html); ggplot (Wickham, 2009; http://ggplot2.org); changepoint (Killick,R., \& Eckley, I.A., 2014; https://www.jstatsoft.org/article/ view/v058i03); strucchange (Zeileis et al., 2002; http://www.jstatsoft.org/v07/i02/).

The waveforms used in this study have been downloaded from European Integrated Data Archive-EIDA (https://www.orfeus-eu.org/data/eida/) and from the Italian Civil Protection (DPC) repository (http://ran.protezionecivile.it/ IT/index.php). Regarding the permanent networks, we used data from the networks with FDSN code: MN, IV, IT (http://www.fdsn.org/networks/).

The moment magnitude used in this study for all earthquakes larger than 5.7 
have been taken from the Geofon moment tensor catalog (http://geofon.gfzpotsdam.de/eqinfo/ list.php?mode=mt). Only for L'Aquila mainshock, we used the GCMT solution (http://www.globalcmt.org/ CMTsearch.html).

The earthquake locations are taken from the INGV bulletin (http://cnt.rm.ingv.it/ iside). All the Internet sites have last accessed on December 2017. Some of the Figures were prepared with GMT (Wessel and Smith, 1991).

\section{Acknowledgments}

This study has been partially funded by the H2020 project SERA (Seismology and Earthquake Engineering Research Infrastructure Alliance for Europe). Comments from two anonymous Reviewer and the Associate Editor M. Chapman are strongly acknowledged. We thank L. Zaccarelli, G. Soldati and L. Faenza for providing their results on velocity variations used in Figure 10.

\section{References}

Abercrombie, R.E. (2014).Stress drops of repeating earthquakes on the San Andreas Fault at Parkfield, Geophys. Res.Lett. 41, 87848791, doi:10.1002/ 2014GL062079.

Aki, K., (1967). Scaling law of seismic spectrum, J. geophys. Res. 72, 12171231.

Ameri, G., S. Drouet, P. Traversa, D. Bindi and F. Cotton (2017). Toward an empirical ground motion prediction equation for France: accounting for regional differences in the source stress parameter, Bull. Earthquake Eng. 
15, 46814717, DOI 10.1007/s10518-017-0171-1

Anderson, J. G., and Y. Lei (1994). Nonparametric Description of Peak Acceleration as a Function of Magnitude, Distance, and Site in Guerrero, Mexico, Bull. Seismol. Soc. Am. 84, no. 4, 1003-1017

Bai J. (1994). Least Squares Estimation of a Shift in Linear Processes, Journal of Time Series Analysis, 15, 453-472

Baltay, A. and T.C. Hanks (2014). Understanding the magnitude dependence of PGA and PGV in NGAWest 2 data, Bull. Seism. Soc. Am. 104, 2851-2865, https://doi.org/10.1785/0120130283

Baltay, A., T. C. Hanks, and N. A. Abrahamson (2017). Uncertainty, Variability, and Earthquake Physics in Ground-Motion Prediction Equations, Bull. Seismol. Soc. Am. 107, no. 4, doi: 10.1785/0120160164.

Bates D., M. Maechler, B. Bolker, and S. Walker (2015). Fitting Linear Mixed-Effects Models Using lme4. Journal of Statistical Software 67, 1, $1-48$.

Bindi D., S. Parolai, H. Grosser, C. Milkereit, and E. Durukal (2007). Empirical ground-motion prediction equations for northwestern Turkey using the aftershocks of the 1999 Kocaeli earthquake, Geophys. Res. Lett. 34, no. 8, doi: 10.1029/2007GL029222.

Bindi, D., Spallarossa, D. and F. Pacor (2017). Between-event and between-station variability observed in the Fourier and response spectra domains: comparison with seismological models, Geophys. J. Int. 210, doi: $10.1093 /$ gji $/$ ggx 217

Bindi, D., Spallarossa, D., Picozzi M., Scafidi, D., and F. Cotton (2018). Impact of Magnitude Selection on Aleatory Variability Associated with 
Ground-Motion Prediction Equations: Part ILocal, Energy, and Moment Magnitude Calibration and Stress-Drop Variability in Central Italy, Bull. Seism Soc. Am., doi: 10.1785/0120170356

Boore, D. M., and Atkinson, G. M., (1989). Spectral scaling of the 19851988 Nahanni, Northwest Territories, earthquakes, Bull. Seism Soc. Am. $\mathbf{7 9}, 17361761$.

Brenguier, F., M. Campillo, C. Hadziioannou, N. M. Shapiro, R. M. Nadeau, and E. Larose (2008), Postseismic relaxation along the San Andreas Fault at Parkfield from continuous seismological observations, Science, 321, 14781481, doi:10.1126/science.1160943.

Brune, J.N., (1970). Tectonic stress and the spectra of shear waves from earthquakes, J. geophys. Res., 75, 49975009.

Castro, R. R., Anderson, J.G. and Singh, S.K., (1990). Site response, attenuation and source spectra of $\mathrm{S}$ waves along the Guerrero, Mexico, subduction zone, Bull. Seism Soc. Am., 80, 14811503.

Causse, M., Cotton, F., and Mai, P. M. (2010). Constraining the roughness degree of slip heterogeneity. J. Geophys. Res.: Solid Earth 115(B5), doi:10.1029/2009JB006747

Chen, J. H., Froment, B., Liu, Q. Y. and Campillo, M. (2010). Distribution of seismic wave speed changes associated with the 12 May $2008 \mathrm{Mw} 7.9$ Wenchuan earthquake. Geophys. Res. Lett. 37, L18302, doi:10.1029/2010GL044582

Chen, X. and P. M. Shearer (2013). California foreshock sequences suggest aseismic triggering process, Geophys. Res. Lett. 40, 26022607, doi:10.1002/grl.50444

Chiaraluce, L., L. Valoroso, D. Piccinini, R. Di Stefano, and P. De Gori 
(2011). The anatomy of the 2009 LAquila normal fault system (central Italy) imaged by high resolution foreshock and aftershock locations, J. Geophys. Res.116, no. B12, doi: 10.1029/2011JB008352.

Chiaraluce, L., R. Di Stefano, E. Tinti, L. Scognamiglio, M. Michele, E. Casarotti, M. Cattaneo, P. De Gori, C. Chiarabba, G. Monachesi, A. Lombardi, L. Valoroso, D. Latorre, and S. Marzorati (2017). The 2016 Central Italy Seismic Sequence: A First Look at the Mainshocks, Aftershocks, and Source Models, Seismol Res Lett 88, no 3, doi: 10.1785/0220160221

Cotton, F., R. Archuleta, and M. Causse (2013). What is sigma of the stress drop?, Seismol. Res. Lett. 84, 4248, doi:10.1785/0220120087.

De Gori, P., F. P. Lucente, and C. Chiarabba (2015), Stressing of fault patch during seismic swarms in central Apennines, Italy, Geophys. Res. Lett. 42, 21572163, doi:10.1002/2015GL063297.

Di Luccio, F., Ventura, G., Giovambattista, R.D., Piscini, A. and Cinti, F.R., (2010). Normal faults and thrusts reactivated by deep fluids: the 6 April 2009 Mw 6.3 L'Aquila earthquake, central Italy, J. geophys. Res. 115, B06315, doi:10.1029/2009JB007190.

Eshelby, J. D. (1957). The determination of the elastic field of an ellipsoidal inclusion and related problems, Proc. R. Soc. London A 441, 376396 .

Gualandi, A., C. Nichele, E. Serpelloni,L. Chiaraluce, L. Anderlini, D. Latorre,M. E. Belardinelli, and J.-P. Avouac (2017), Aseismic deformation associated with an earthquake swarm in the northern Apennines (Italy), Geophys. Res. Lett. 44, 77067714, doi:10.1002/2017GL073687.

Hanks, T.C., and H. Kanamori (1979). A moment-magnitude scale, J. 
geophys.Res. 84, 23482350

Heckels,R.E.G., M. K. Savage and J. Townend (2018). Postseismic velocity changes following the $2010 \mathrm{Mw} 7.1$ Darfield earthquake, New Zealand, revealed by ambient seismic field analysis, Geophys. J. Int, ggy021, https://doi.org/10.1093/gji/ggy021

Keilis-Borok, V. (1959). On the estimation of the displacement in an earthquake source and of source dimension, Ann. Geofisc. 12, 205214.

Killick,R., and Eckley, I.A., (2014). Changepoint: An R Package for Changepoint Analysis J. of Statistical Software, 58,1-19

Konno, K, and T. Ohmachi (1998). Ground-motion characteristics estimated from spectral ratio between horizontal and vertical components of microtremor, Bull Seismol Soc Am 88, 228241

Li, Y. G., J. E. Vidale, K. Aki, F. Xu, and T. Burdette (1998). Evidence shallow fault zone strengthening after the 1992 M7.5 Landers, California earthquake, Science 279, 5348, 217219.

Luzi L, Puglia R, Russo E and ORFEUS WG5 (2016). Engineering Strong Motion Database, version 1.0. Istituto Nazionale di Geofisica e Vulcanologia, Observatories \& Research Facilities for European Seismology. doi: $10.13127 / \mathrm{ESM}$

Mai, P. M., Galis, M., Thingbaijam, K. K., Vyas, J. C., and Dunham, E.M. (2017). Accounting for fault roughness in pseudo-dynamic groundmotion simulations. Pure and Applied Geophysics, 174, 3419-3450.

Marone, C. (1998). The effect of loading rate on static friction and the rate of fault healing during the earthquake cycle, Nature 391, 69-72

McLaskey, G. C., A. M. Thomas, S. D. Glaser and R. M. Nadeau 
(2012).Fault healing promotes high-frequency earthquakes in laboratory experiments and on natural faults, Nature 491, doi:10.1038/nature11512

Oth, A., Bindi, D., Parolai, S. and Di Giacomo, D., (2011). Spectral analysis of K-NET and KiK-net data in Japan, Part II: On attenuation characteristics, source spectra, and site response of borehole and surface stations, Bull.seism. Soc. Am. 101, 2, 667- 687.

Oth, A., H. Miyake and D. Bindi (2017). On the relation of earthquake stress drop and ground motion variability, J. Geophys. Res. Solid Earth 122, doi:10.1002/2017JB014026.

Pacor, F., Spallarossa, D., A. Oth, L. Luzi, R. Puglia, L. Cantore, A. Mercuri, M. D’Amico, and D., Bindi (2016). Spectral models for ground motion prediction in the L'Aquila region (central Italy): Evidence for stressdrop dependence on magnitude and depth, Geophys. J. Int., 204, 697718.

Peng,Z., and Y Ben-Zion (2006). Temporal changes of shallow seismic velocity around the Karadere-Dzce branch of the north Anatolian fault and strong ground motion Pure and Applied Geophysics 163, 567-600, doi $10.1007 / \mathrm{s} 00024-005-0034-6$

Piña-Valdés, J., A. Soquet, F. Cotton and S. Specht (2018). Spatiotemporal variations of ground motion in northern Chile before and after the $2014 \mathrm{Mw} 8.1$ Iquique megathrust, Bull. Seism. Soc. Am., DOI: https://doi.org/10.1785/0120170052

Purvance, M. D., and Anderson, J. G. (2003). A comprehensive study of the observed spectral decay in strong-motion accelerations recorded in Guerrero, Mexico. Bull.seism. Soc. Am. 93, 600-611.

R Development Core Team (2008). R: A language and environment 
for statistical computing. R Foundation for Statistical Computing, Vienna, Austria. ISBN 3-900051-07-0

Scuderi, M. M., C. Marone, E. Tinti, G. Di Stefano, and C. Collettini (2016), Precursory changes in seismic velocity for the spectrum of earthquake failure modes, Nat. Geosci., 9, 695-700.

Soldati, G., L. Zaccarelli, L. Faenza and A. Michelini (2015). Monitoring of crustal seismic velocity variations in the LAquila fault zone inferred from noise cross-correlation, Geophys. J. Int 202, 604-611, doi: $10.1093 /$ gji/ggv172

Soquet, A., J. Piña-Valdés, J. Jara, F. Cotton, A. Walpersdorf, N. Cotte, S. Specht, F. Ortega-Culuciati, D. Carrizo and E. Norabuena (2016). An 8-month slow slip event triggers progressive nucleation of the 2014 Chile megathrust, Geophys. Res. Lett. 44, 9, 4046-4053 doi: 10.1002/2017GL073023

Trugman, D. T., and P. M. Shearer (2018). Strong Correlation between Stress Drop and Peak Ground Acceleration for Recent M 14 Earthquakes in the San Francisco Bay Area , Bull. Seism. Soc. Am., DOI: https://doi.org/10.1785/ 0120170245

Valoroso, L., Chiaraluce, L., Di Stefano, R., and Monachesi, G. (2017). Mixed-mode slip behavior of the Altotiberina low-angle normal fault system (Northern Apennines, Italy) through high-resolution earthquake locations and repeating events. Journal of Geophysical Research: Solid Earth 122, 10,22010,240, doi:10.1002/2017JB014607

Wessel, P., and W. H. F. Smith (1991). Free software helps map and display data, EOS Trans. Amer. Geophys. U. 72, no. 41, pp. 441, 445-446

Wickham, H. (2009). ggplot2: Elegant Graphics for Data Analysis. 
Springer-Verlag New York, isbn 978-0-387-98140-6

Wooddell, K. E., and Abrahamson, N. A., (2014). Classification of main shocks and aftershocks in the NGA-West2 database, Earthquake Spectra 30, 12571267

Wu, Q. and M. Chapman (2017). Stress-Drop Estimates and Source Scaling of the 2011 Mineral, Virginia, Mainshock and Aftershocks, Bull. Seism. Soc. Am. 107, 2703-2720

Yoshida, K., T. Saito, Y. Urata, Y. Asano, A. Hasegawa (2017). Temporal changes in stress drop, frictional strength, and earthquake size distribution in the 2011 Yamagata-Fukushima, NE Japan, earthquake swarm, caused by fluid migration, Journal of Geophysical Research: Solid Earth 122, 10,37910,397. https://doi.org/10.1002/2017JB014334

Zeileis A., Leisch F., Hornik K., Kleiber C. (2002) strucchange: An R Package for Testing for Structural Change in Linear Regression Models, Journal of Statistical Software, 7, 2, 138

Zeileis,A., C. Kleiber, W. Krämer, and K. Hornik (2003) Testing and dating of structural changes in practic Computational Statistics \& Data Analysis, 44, 109-123 


\section{${ }_{556}$ Figure captions}

565

Figure 1. Map of earthquake epicenters (circles) analyzed in this study (see Data and Resources section). Circles are filled according to the latitude of the epicenter, assuming arbitrary thresholds at latitudes 42.4 and 42.68 . A few earthquakes belonging to the 2014 Gubbio swarm are also included. The focal mechanisms of earthquakes with magnitude larger than 6 are shown as beach ball taken from Geofon and from the Global Centroid Moment Tensor catalogs (see Data and Resources section). The rectangles depict the surface projection of the faults as given in Luzi et al. (2016).

Figure 2. Scaling relationships between stress drop $\Delta \sigma$, hypocentral depth and moment magnitude $\mathrm{Mw}$ for the earthquakes analyzed in this study (Bindi et al., 2018). The trend-lines are estimated through a local regression (Loess) performed using the ggplot2 package in R (Wickham, 2009).

Figure 3. Observation minus prediction residuals versus predictor variables for the model in equation (1). The residual $\epsilon$ versus distance and the between event $\delta B_{e}$ versus moment magnitude $\mathrm{Mw}$ are shown for the regressions performed at $0.75 \mathrm{~Hz}$ (left) and $10 \mathrm{~Hz}$ (right).

Figure 4. (a) Between-event residuals $\left(\delta B_{e}\right)$ versus time, at $10 \mathrm{~Hz}$. Earthquakes belonging to the Gubbio swarm (triangles; see Figure 1) are not considered for the evaluating the local-trend analysis; zooms over different time windows are presented in Figure S3 of the electronic supplements to this article. (b) Between-event versus time, at $0.75 \mathrm{~Hz}$. (c) the same as in 
(b) but zooming over the 2016 sequence. Vertical bars represent the $95 \%$ confidence interval for $\delta B_{e}$.

Figure 5.Between-event $\delta B_{e}$ residuals versus stress drop $\Delta \sigma$ (top) and hypocentral depth (bottom), considering the results for $0.75 \mathrm{~Hz}$ (left) and $10 \mathrm{~Hz}$ (right).

Figure 6.Person correlation coefficients between $\Delta \sigma$ and $\delta B_{e}$ at different frequencies.

Figure 7. Temporal variability of stress drop $\Delta \sigma$. (a) complete distribution of earthquakes; (b) only earthquakes located in proximity of the 2009 L' Aquila mainshock ; (c) only earthquakes occurred in the Campotosto segment; (d) earthquakes occurred in the area corresponding to the 2016-17 mainshocks. For the location of the earthquakes in panels (b) through (d), see Figure 1. Vertical bars represent the $95 \%$ confidence interval for $\Delta \sigma$. Zooms over different windows are available in Figure 8.

Figure 8. Temporal variability of stress drop $\Delta \sigma$, different zooms of Figure 7.

Figure 9. Results of the breakpoint analysis (Zeileis et al., 2002; 2003). A change in the linear trend with of $\Delta \sigma$ (dashed lines) is detected between February 10 and March 8, 2014 (vertical gray line). Details of the analysis are reported in the electronic supplements to this article.

Figure 10. Comparison between the relative shear wave velocity variation computed by Soldati et al (2015) (points) and the $\Delta \sigma$ (squares) time variability. 
${ }_{603}$ Figures 


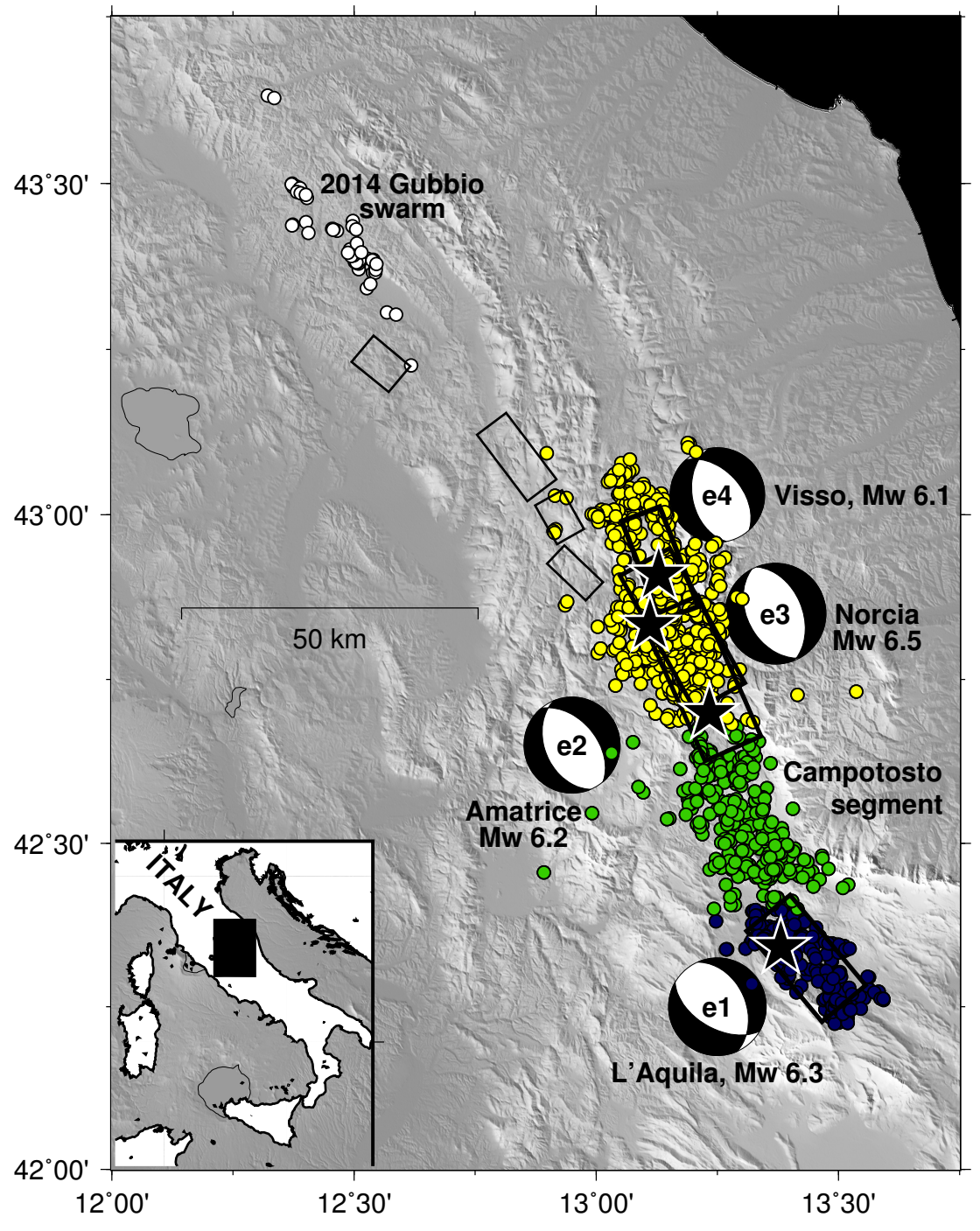

Figure 1: 

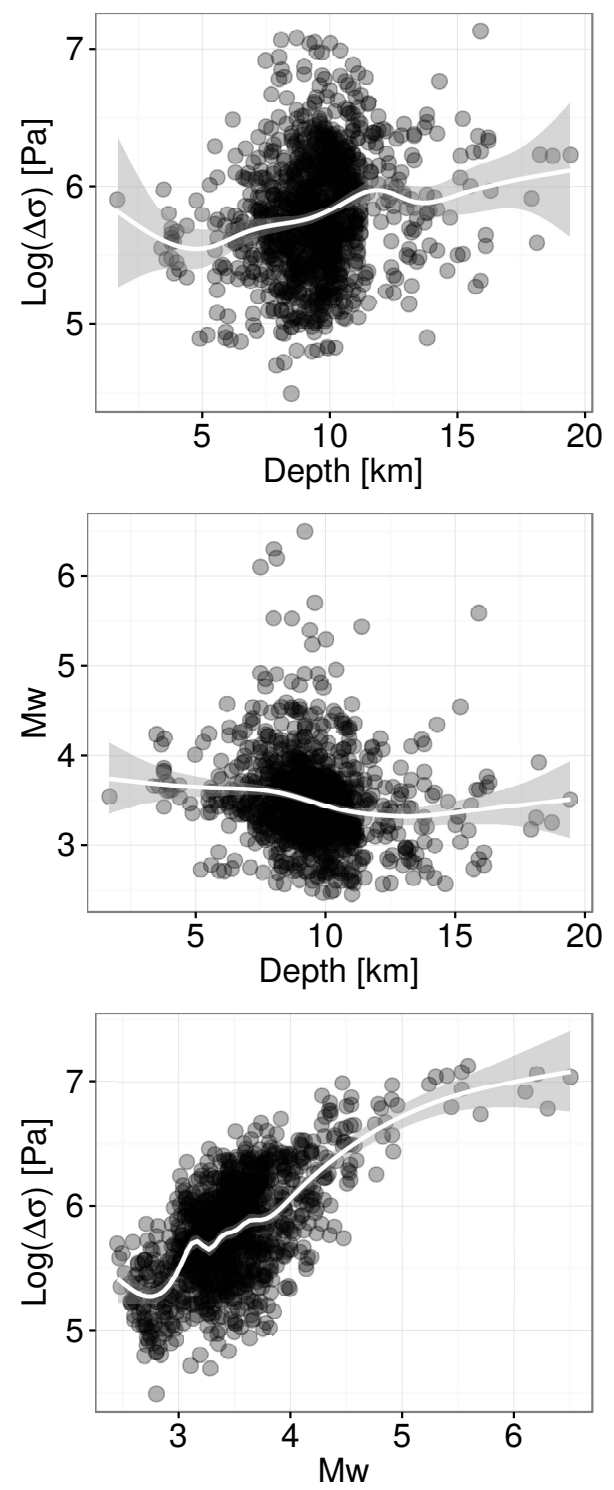

Figure 2: 

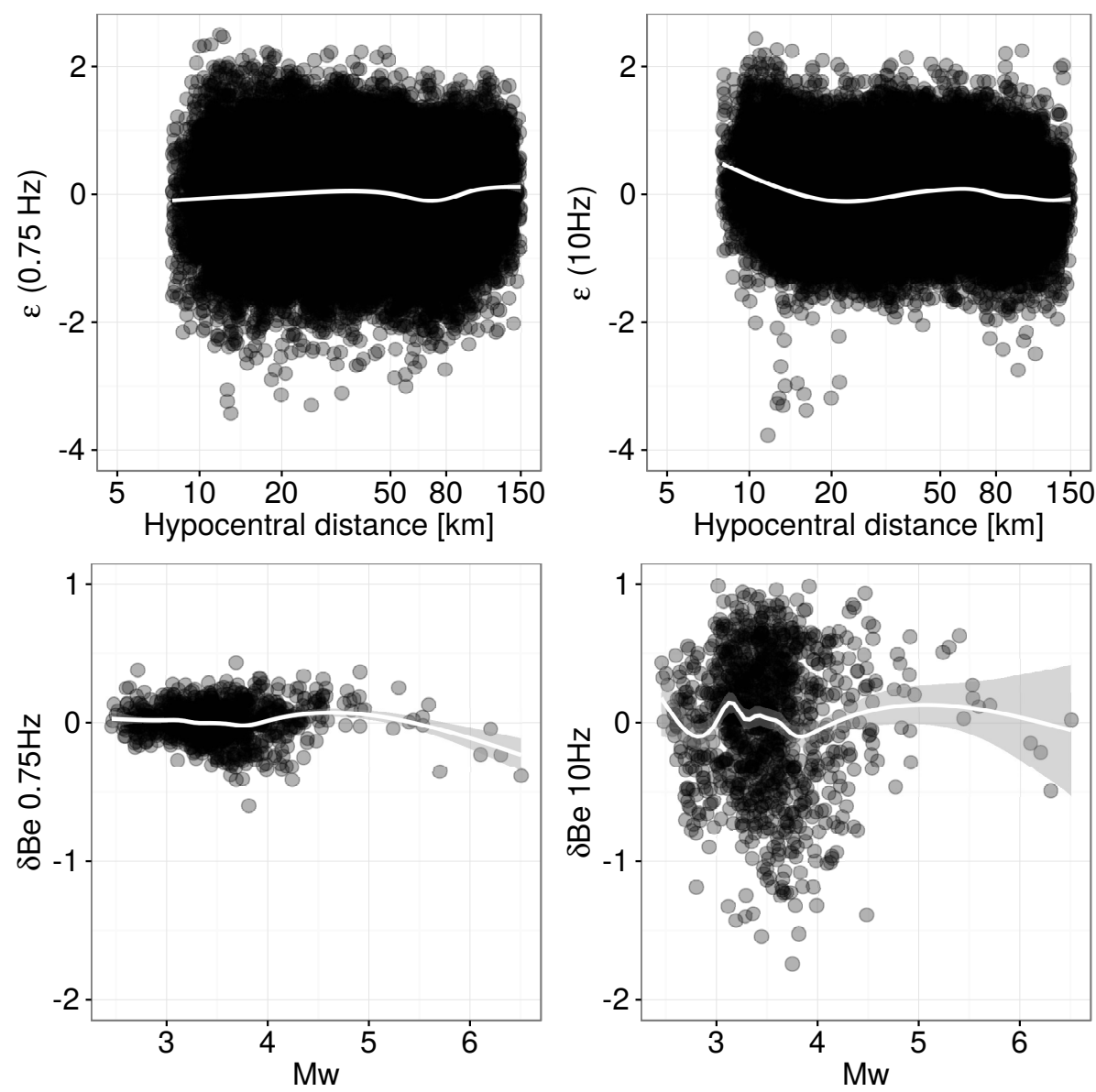

Figure 3: 
(a)

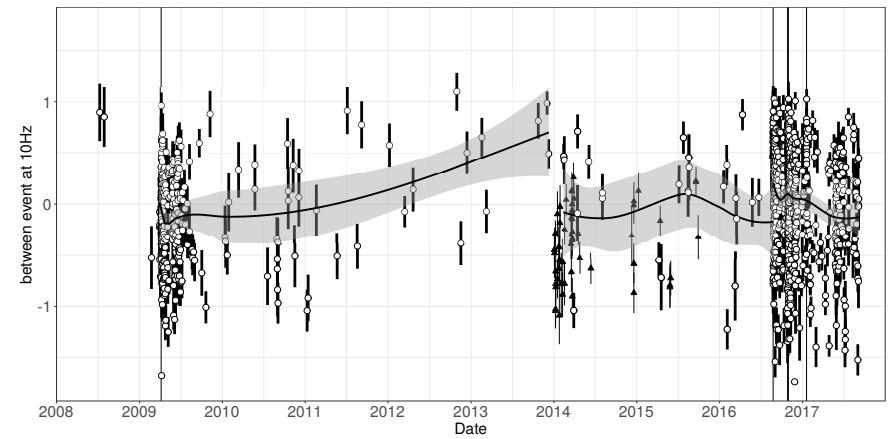

(b)

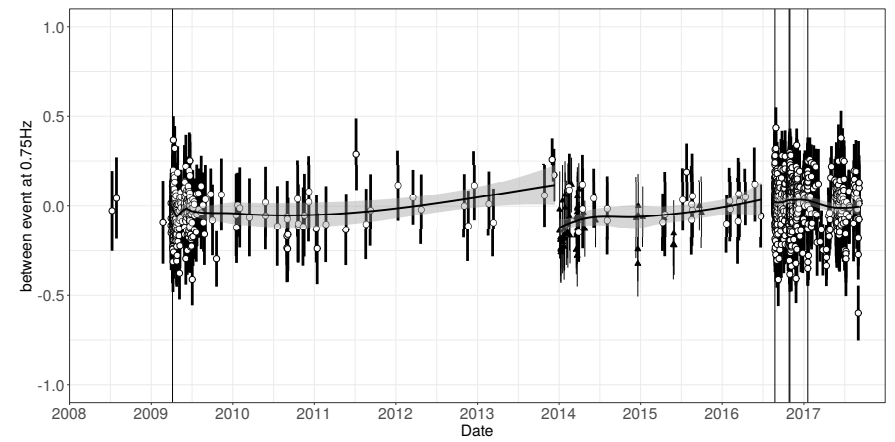

(c)

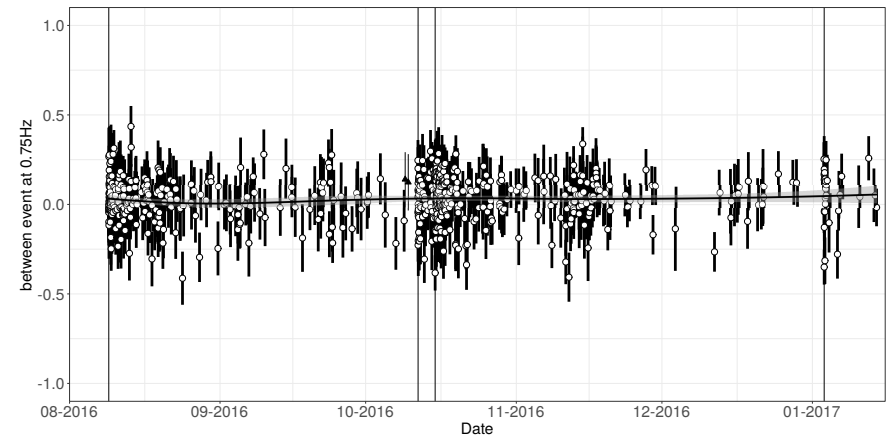

Figure 4: 

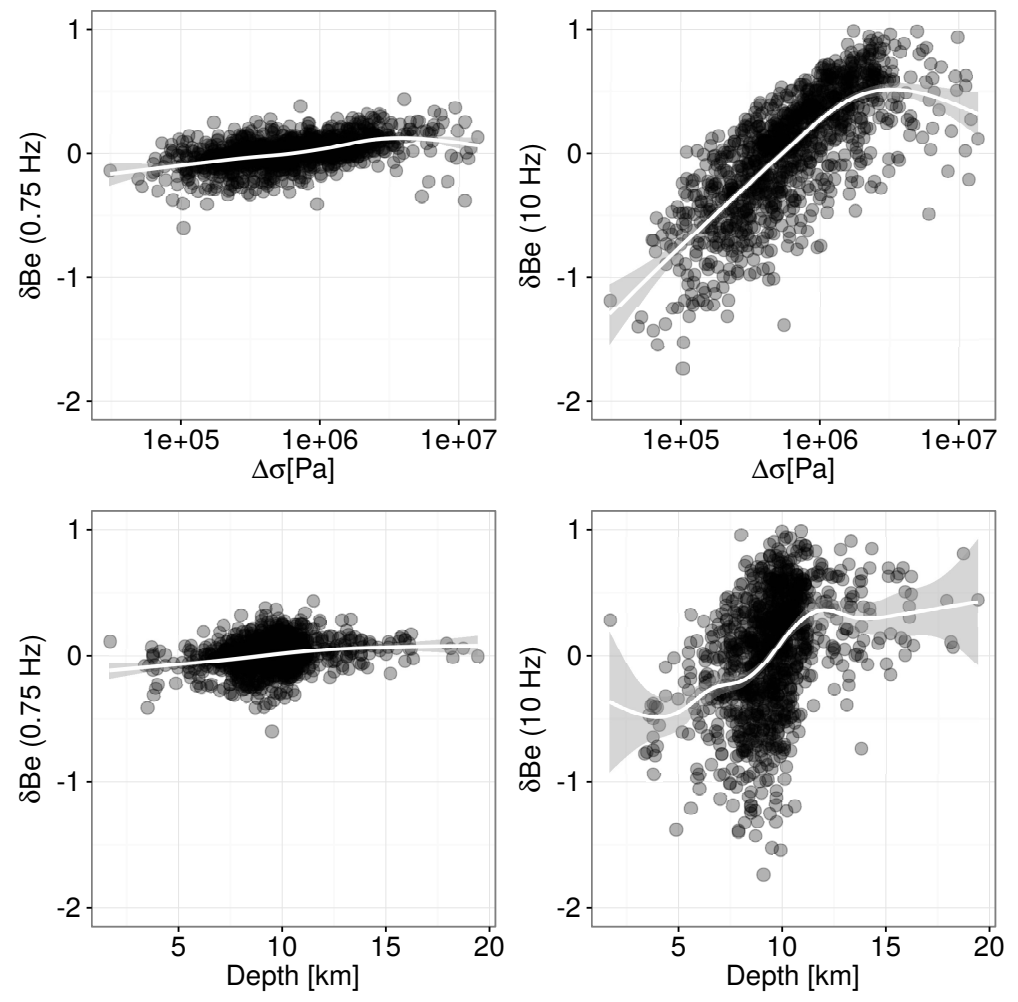

Figure 5: 


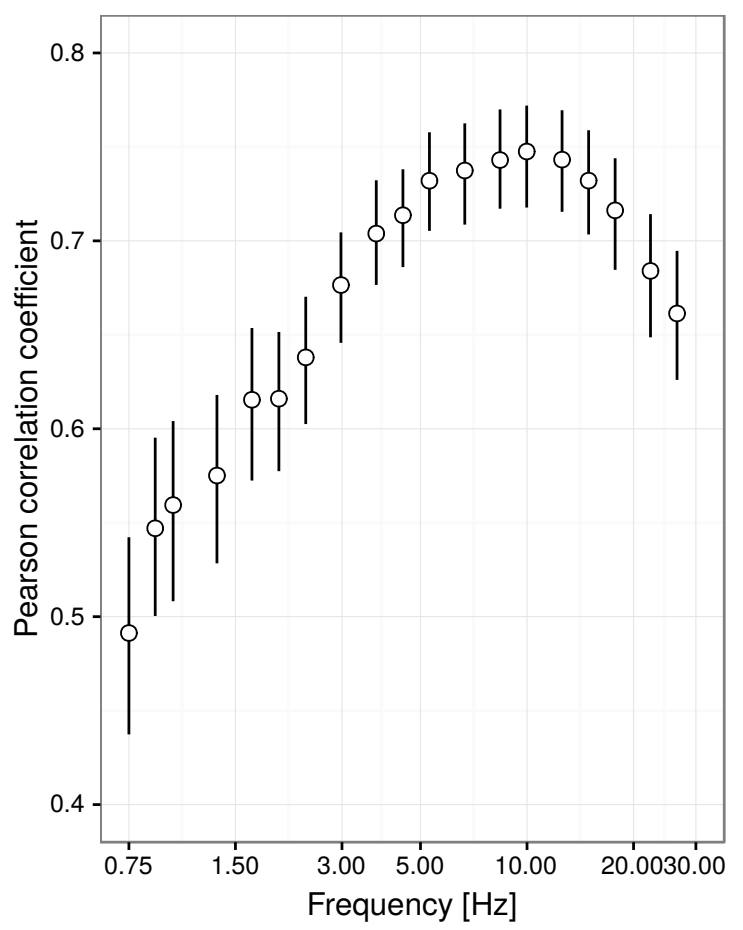

Figure 6: 
(a)

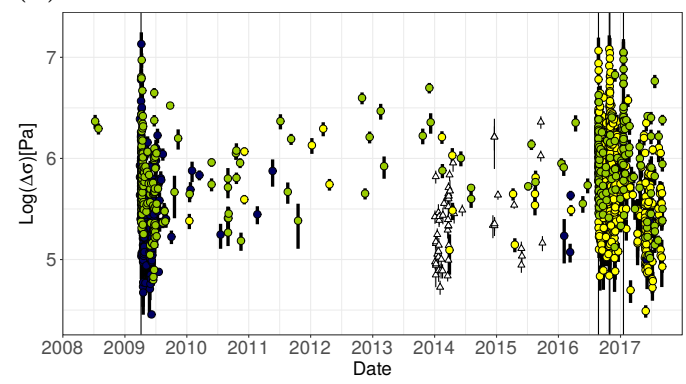

(b)

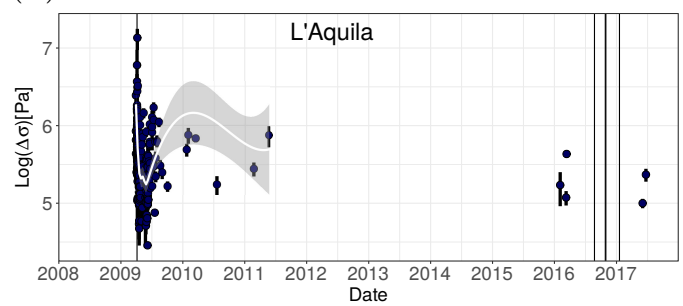

(c)

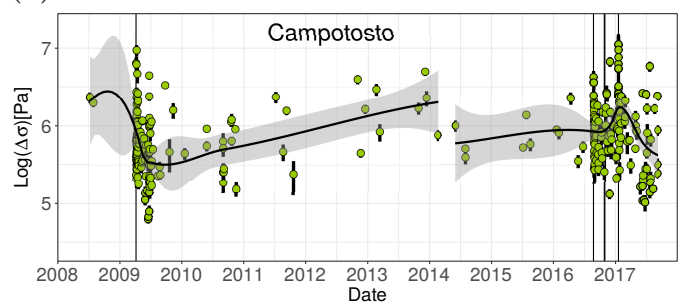

(d)

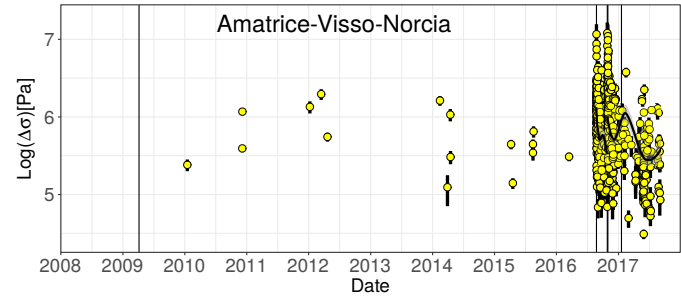

Figure 7: 


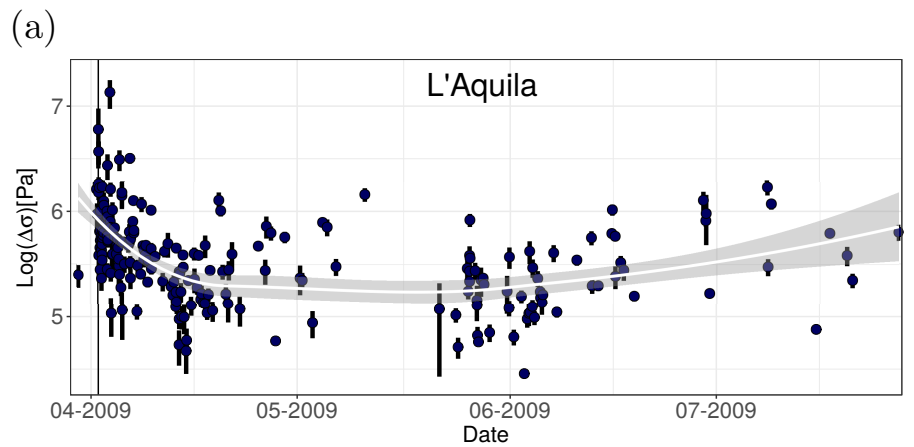

(b)

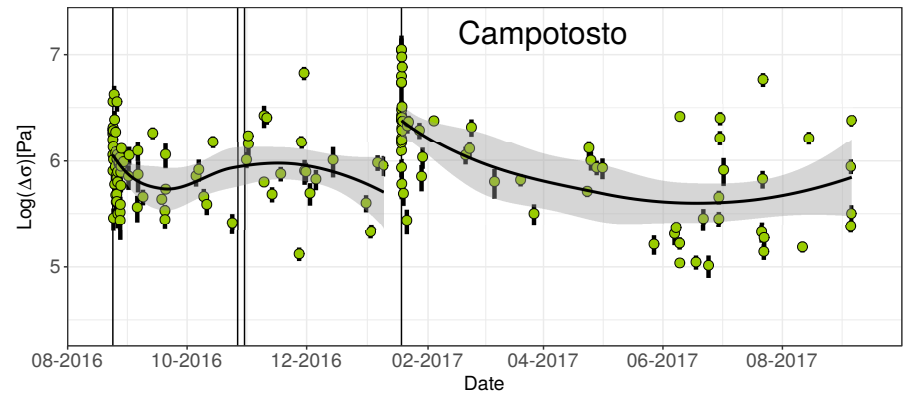

(c)

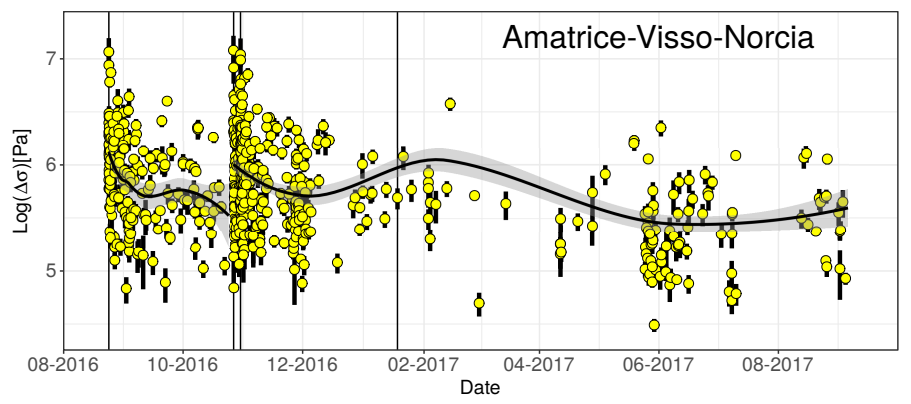

Figure 8: 


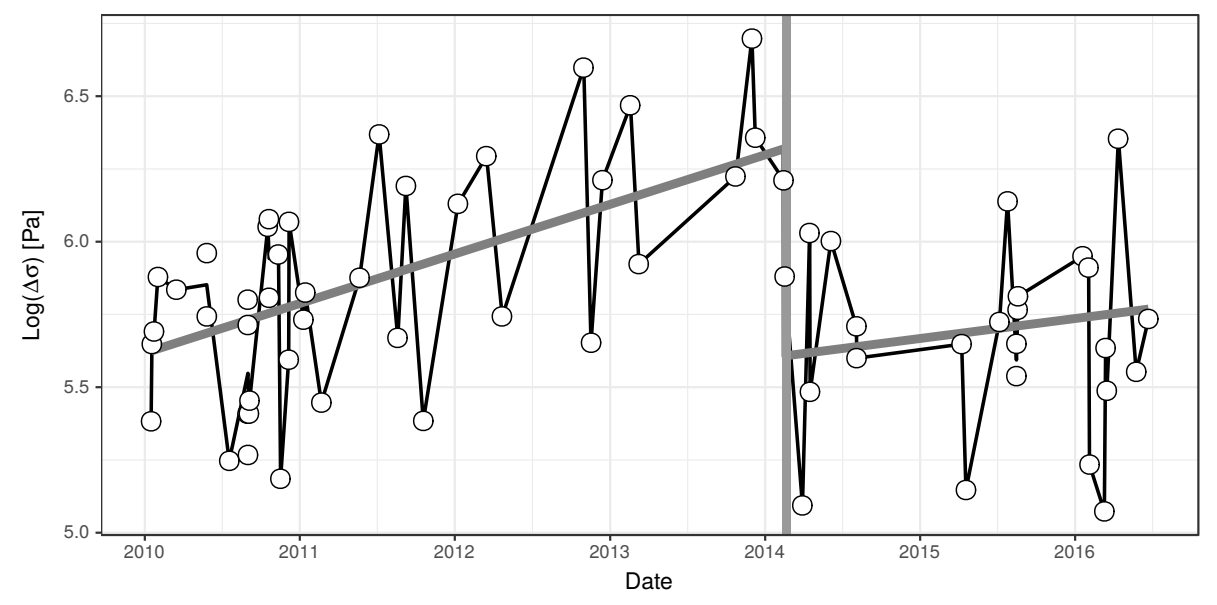

Figure 9: 


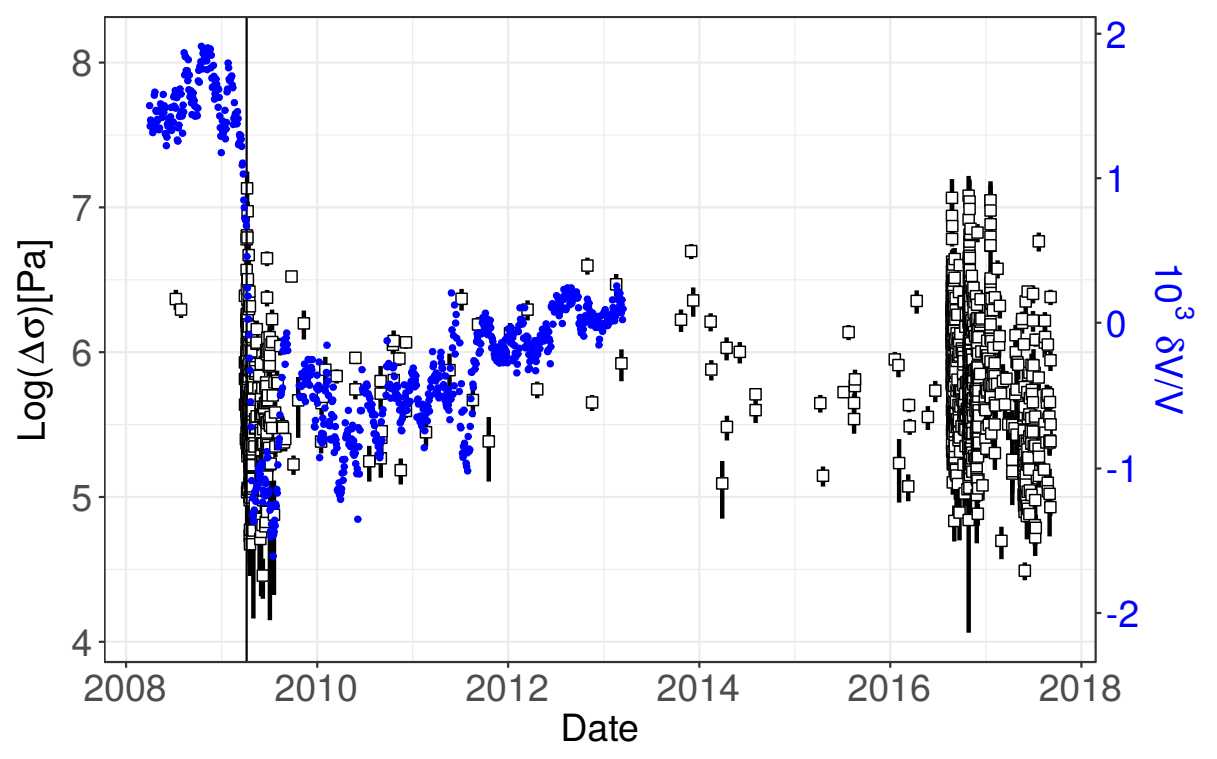

Figure 10: 


\title{
Temporal variability of ground-shaking and stress drop in central Italy: a hint for fault healing?
}

\author{
D. Bindi, F. Cotton, D. Spallarossa, M. Picozzi, and E. Rivalta
}

This Supplementary Material includes additional Figures cited in the main article. In figure S1, a map with the locations of stations used in this study is provided. The map in Figure S2 shows the earthquake locations as in Figure 1 but with symbols filled according to the time elapsed since the L'Aquila earthquake. Figure S3 complements Figure 4 by showing the variability with time of the between event residuals $\delta \mathrm{B}_{\mathrm{e}}$ at $10 \mathrm{~Hz}$ considering different time windows. In Figure $\mathrm{S} 4$, the symbols used to depict the time dependency of $\delta \mathrm{B}_{\mathrm{e}}$ at $10 \mathrm{~Hz}$ are filled according to the logarithm of the stress drop $\Delta \sigma$, measured in [Pa]. Finally, in Figure S5, the symbols used to show the time variability of $\Delta \sigma$ are filled according to the moment magnitude $\mathrm{Mw}$.

The Supplementary Material includes also Table S1, listing the frequency-dependent coefficients of the Ground Motion Prediction Equation developed in this study (equation 6) for the Fourier amplitude spectra. Finally, the Supplementary Material includes additional text describing both the error propagation applied for $\Delta \sigma$ and the break-point analysis performed for locating the $\Delta \sigma$ change-point occurred at the beginning of 2014. 


\section{Error propagation}

The non-parametric source spectra $S(f)$ obtained through the non-parametric Generalized Inversion (Bindi et al., 2017) are described in terms of acceleration source model (Brune, 1970):

$S_{\text {Brune }}(f)=$ const $M_{0} \frac{f^{2}}{1+\left(\frac{f}{f_{c}}\right)^{2}}$

where $M_{o}$ is the seismic moment, $f_{c}$ the corner frequency and const is a constant depending on the radiation pattern, free surface amplification, density and velocity at the source location. We fit the $S_{\text {Brune }}(f)$ model to $S(f)$ by computing the logarithm (hereinafter we refer to the logarithm in base 10 as $\log$ and to the natural logarithm as $\ln$ ) of the spectra and considering as independent variables $\log \left(M_{o}\right)$ and $f_{c}$. The fit is performed following a non-linear least-squares approach and the variancecovariance matrix $v C o v$ is evaluated. From the square root of the diagonal of $v C o v$, we extracted the standard errors on $f_{c}$ and on $\log \left(M_{o}\right)$, referred to as $\delta_{\mathrm{fc}}$ and $\delta_{\log M o}$, and from the off-diagonal elements the correlation between $f_{c}$ and $\log \left(M_{o}\right)$, indicated as $\delta_{(f c, \log M o)}$. The error propagation is evaluated through the variance formula for correlated variables, truncated at the first order of the Taylor's expansion:

$\delta_{\Delta \sigma}^{2}=\left(\frac{\partial \Delta \sigma}{\partial f_{c}}\right)^{2} \delta_{f_{c}}^{2}+\left(\frac{\partial \Delta \sigma}{\partial \log \left(M_{o}\right)}\right)^{2} \delta_{\log M_{o}}^{2}+2 \delta_{\left(f_{c}, \log M_{o}\right)} \frac{\partial \Delta \sigma}{\partial f_{c}} \frac{\partial \Delta \sigma}{\partial \log \left(M_{o}\right)}$

The stress drop $\Delta \sigma$ is computed from $M_{o}$ and $f_{c}$ using the following relationships (Eshelby, 1957; Brune 1970):

$\Delta \sigma=\frac{7}{16} \frac{M_{o}}{r^{3}}$

$r=2.34 \frac{v_{S}}{2 \pi f_{c}}$

where $v_{s}$ is the shear-wave velocity at the source. Considering the logarithm of $\Delta \sigma$, equations (S3) and (S4) give

$\log (\Delta \sigma)=$ constant $+\log \left(M_{o}\right)+3 \log \left(f_{c}\right)$

and equation (2) becomes

$\delta_{\log (\Delta \sigma)}^{2}=\left(\frac{\partial \log (\Delta \sigma)}{\partial f_{c}}\right)^{2} \delta_{f_{c}}^{2}+\left(\frac{\partial \log (\Delta \sigma)}{\partial \log \left(M_{o}\right)}\right)^{2} \delta_{\log M_{o}}^{2}+2 \delta_{f_{c}, \log M_{o}} \frac{\partial \log (\Delta \sigma)}{\partial f_{c}} \frac{\partial \log (\Delta \sigma)}{\partial \log \left(M_{o}\right)}$

From equation (5),

$\frac{\partial \log (\Delta \sigma)}{\partial \log \left(M_{o}\right)}=1 \frac{\partial \log (\Delta \sigma)}{\partial f_{c}}=\frac{3}{\ln (10)} \frac{1}{f_{c}}$

Using (7) in (6), we obtain

$\delta_{\log (\Delta \sigma)}^{2}=\frac{9}{[\ln (10)]^{2}}\left(\frac{\delta_{f_{c}}}{f_{c}}\right)^{2}+\delta_{\log M_{o}}^{2}+\delta_{\left(f_{c}, \log M_{o}\right)} \frac{6}{\ln (10)} \frac{1}{f_{c}}$

The error propagation in equation (S8) is similar to the one described by Cotton et al (2013), in their equation (9). The differences are related to a different choice of the variables, since they used $\log \left(f_{c}\right)$ while we used $f_{c}$, and to the fact that Cotton et al (2013) neglected the cross-term of the covariance matrix. The advantage of using $\log \left(f_{c}\right)$ is that equation (S5) becomes linear with respect to the variables and, therefore, equation (S2) is exact. The drawback is that in fitting the Brune model, the dependence on the variable takes the more complex form of $10^{\log (f c)}$. Regarding the cross-term, since $\delta_{(f c, l o g M o}$ is negative, the choice of Cotton et al (2013) was conservative.

Finally, since $\delta_{\Delta \sigma}=\ln (10) \Delta \sigma \delta \log (\Delta \sigma)$, from equation (S8) we get the standard error on $\Delta \sigma$

$\delta_{\Delta \sigma}=\Delta \sigma \sqrt{9\left(\frac{\delta_{f_{c}}}{f_{c}}\right)^{2}+[\ln (10)]^{2} \delta_{\log M_{o}}^{2}+\frac{6 \ln (10)}{f_{c}} \delta_{\left(f_{c}, \log M_{o}\right)}}$

Figure S6 shows the 95\% confidence interval, computed as 1.96 times the standard error, for the data analyzed in this study. Zooms over different time windows are shown in Figure S7.

\section{Breakpoint analysis}


In order to assess the statistical significance of the abrupt drop in $\Delta \sigma$ occurring at the beginning of 2014, we performed a change-point analysis (Page, 1954; Jaiswal et al., 2015). The analysis was performed though the following steps, outlined in Figure S8:

- we considered $\Delta \sigma$ values between January 2010 and June 2016 (Figure S8a);

- since the time series is unevenly sampled, we applied and interpolation scheme. After some tests using different approaches, we used a simple linear interpolation between consecutive samples. The time series interpolated using a regular sampling of 1 day is shown in Figure S8b;

- A preliminary detection in terms of significant change in the average was performed following the approach of Killick and Eckley (2014). The detected change point (Figure S8c) is located on February 15, 2014;

-finally, the breakpoint analysis of Zeileis et al (2003) was applied to identify and locate a change in the coefficients of the linear regression with time. Figure S8d shows the location of the change point with its 95\% confidence interval (corresponding to the period from February, 10 to March, 8) and the best linear models before and after the change point.

\section{Table caption}

Table S1. Coefficients $\left(\mathrm{e}_{1}, \mathrm{~b}_{1}, \mathrm{~b}_{2}, \mathrm{c}_{1}, \mathrm{c}_{2}, \mathrm{c}_{3}\right)$ of the Fourier ground motion prediction equation described in equation (6); $\phi_{\mathrm{s} 2 \mathrm{~s}}, \tau, \phi_{0}$ are the standard deviation of the between station $\delta \mathrm{Bs}$, of the between event $\delta \mathrm{Be}$ and residual $\varepsilon$ distributions (see equation 6 ).

\section{Figure captions}

Figure S1 Location of stations considered in this study.

Figure S2 Location of earthquakes considered in this study with symbols filled according to the earthquake origin time with respect to April 6, 2009 (see also Figure 1).

Figure S3 Between-event residuals $\delta$ Be versus time at $10 \mathrm{~Hz}$ for different time intervals (see also Figure 4).

Figure S4 Between-event residuals $\delta$ Be versus time with symbols filled according to stress drop $\Delta \sigma$. Triangles indicate earthquakes occurred in the area of the 2013-14 Gubbio swarm, see Figure 1.

Figure S5 Stress drop $\Delta \sigma$ versus time with symbols filled according to moment magnitude Mw. Triangles indicate earthquakes occurred in the area of the 2013-14 Gubbio swarm, see Figure 1.

Figure S6. 95\% confidence intervals for $\Delta \sigma$.

Figure S7. 95\% confidence intervals for $\Delta \sigma$, for different time intervals.

Figure S8. Change point analysis. a) original data. b) data linearly re-sampled at the rate of one sample per day; c) detection of the change point for the average; d) detection of the change point in the linear regression coefficients

\section{References}

Cotton, F., R. Archuleta and M. Causse (2013). What is the sigma of stress drop, Seism. Res. Lett. 84, 42-48 doi: 10.1785/0220120087

Jaiswal, R. K., Lohani A. K., and H. L. Tiwari (2015). Statistical analysis for change detection and trend, Envirom. Process, 2, 729-749, doi: 10.1007/s40710-015-0101-3

Page, E. S. (1954). Continuous inspection schemes, Biometrika, 41, 100-115 doi 10.1093/biomet/41.1-2.100 
Table S1. Coefficients $\left(\mathrm{e}_{1}, \mathrm{~b}_{1}, \mathrm{~b}_{2}, \mathrm{c}_{1}, \mathrm{c}_{2}, \mathrm{c}_{3}\right)$ of the Fourier ground motion prediction equation described in equation (6); $\phi_{\mathrm{s} 2 \mathrm{~S}}, \tau, \phi_{0}$ are the standard deviation of the between station $\delta \mathrm{Bs}$, of the between event $\delta \mathrm{Be}$ and residual $\varepsilon$ distributions (see equation 6 ).

\begin{tabular}{|c|c|c|c|c|c|c|c|c|c|}
\hline Freq $[\mathrm{Hz}]$ & $\mathbf{e}_{1}$ & $\mathbf{b}_{1}$ & $\mathbf{b}_{2}$ & $\mathbf{c}_{1}$ & $\mathbf{c}_{2}$ & $\mathbf{c}_{3}$ & $\phi \mathrm{s} 2 \mathrm{~s}$ & $\tau$ & $\phi_{0}$ \\
\hline 0.35 & 0.80146 & 2.21669 & -0.04089 & -2.00751 & 0.17379 & 0.00545 & 0.47522 & 0.21587 & 0.70041 \\
\hline 0.4 & 1.04779 & 2.27639 & -0.04779 & -2.07823 & 0.17007 & 0.00764 & 0.47742 & 0.20514 & 0.6891 \\
\hline 0.5 & 1.33959 & 2.42340 & -0.06803 & -2.12578 & 0.15654 & 0.00992 & 0.48835 & 0.18558 & 0.64771 \\
\hline 0.59 & 1.56116 & 2.52567 & -0.1043 & -2.15865 & 0.14717 & 0.01189 & 0.51034 & 0.17384 & 0.6542 \\
\hline 0.75 & 1.92521 & 2.68625 & -0.15401 & -2.18397 & 0.12672 & 0.01265 & 0.54612 & 0.14888 & 0.60759 \\
\hline 0.89 & 2.33067 & 2.71259 & -0.18884 & -2.23543 & 0.1305 & 0.01312 & 0.57532 & 0.14129 & 0.58482 \\
\hline 1 & 2.60114 & 2.72391 & -0.21177 & -2.27032 & 0.12893 & 0.01357 & 0.59266 & 0.14381 & 0.59366 \\
\hline 1.33 & 3.09564 & 2.76270 & -0.23556 & -2.26438 & 0.10171 & 0.01225 & 0.61237 & 0.16665 & 0.56748 \\
\hline 1.67 & 3.48468 & 2.68448 & -0.24237 & -2.27198 & 0.0962 & 0.01163 & 0.61487 & 0.19459 & 0.53169 \\
\hline 1.99 & 3.67784 & 2.62330 & -0.24584 & -2.26209 & 0.0945 & 0.01103 & 0.6234 & 0.22036 & 0.53082 \\
\hline 2.37 & 3.76324 & 2.55504 & -0.23485 & -2.20498 & 0.08715 & 0.00903 & 0.63017 & 0.25424 & 0.52461 \\
\hline 2.98 & 3.59658 & 2.38582 & -0.21798 & -2.04151 & 0.0927 & 0.00468 & 0.60396 & 0.29829 & 0.52005 \\
\hline 3.75 & 3.42988 & 2.25625 & -0.19759 & -1.90391 & 0.08802 & 0.00061 & 0.62728 & 0.34572 & 0.52529 \\
\hline 4.46 & 3.28532 & 2.08639 & -0.17907 & -1.79832 & 0.10474 & -0.00292 & 0.65699 & 0.37856 & 0.5284 \\
\hline 5.3 & 3.07226 & 2.00030 & -0.15746 & -1.69606 & 0.09872 & -0.00611 & 0.69546 & 0.40803 & 0.52817 \\
\hline 6.67 & 2.87406 & 1.86515 & -0.13773 & -1.60836 & 0.10035 & -0.00995 & 0.76182 & 0.44405 & 0.52234 \\
\hline 8.39 & 2.57230 & 1.78698 & -0.11523 & -1.51731 & 0.08999 & -0.01435 & 0.81647 & 0.48376 & 0.52027 \\
\hline 10 & 2.36854 & 1.71378 & -0.09805 & -1.47415 & 0.08535 & -0.01735 & 0.87734 & 0.51209 & 0.51604 \\
\hline 12.56 & 2.31993 & 1.61380 & -0.08088 & -1.50875 & 0.08424 & -0.02057 & 0.96463 & 0.56033 & 0.51112 \\
\hline 14.93 & 2.34572 & 1.50170 & -0.06593 & -1.57316 & 0.09194 & -0.02223 & 102.517 & 0.59434 & 0.51074 \\
\hline 17.74 & 2.35082 & 1.44668 & -0.03929 & -1.67057 & 0.08297 & -0.0224 & 108.441 & 0.63308 & 0.5131 \\
\hline 22.33 & 2.52609 & 1.39944 & -0.01618 & -1.91863 & 0.06611 & -0.01832 & 112.420 & 0.68558 & 0.52859 \\
\hline 26.54 & 2.67305 & 1.39498 & 0.01618 & -2.11285 & 0.04734 & -0.01503 & 109.470 & 0.70831 & 0.52971 \\
\hline
\end{tabular}




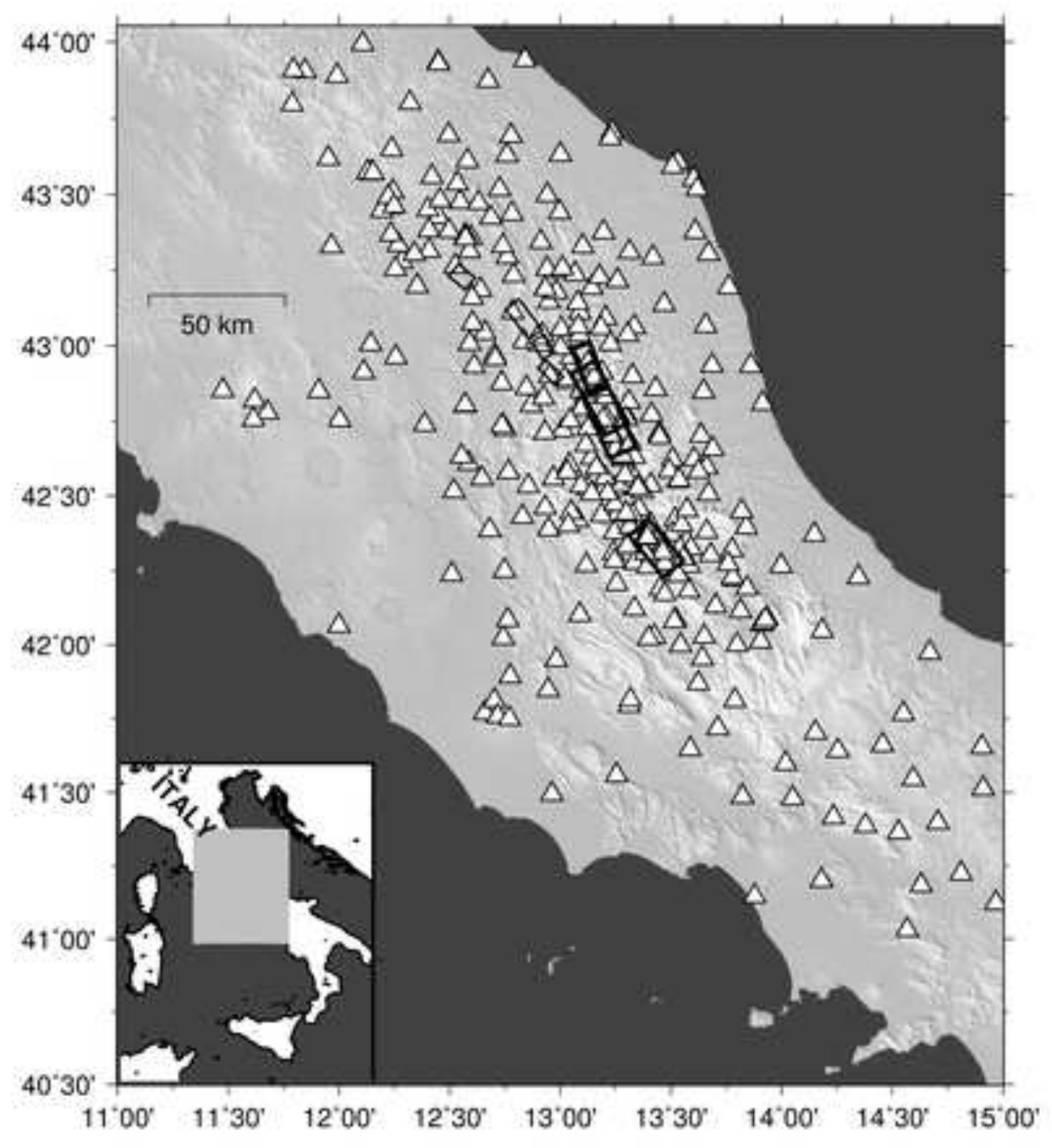




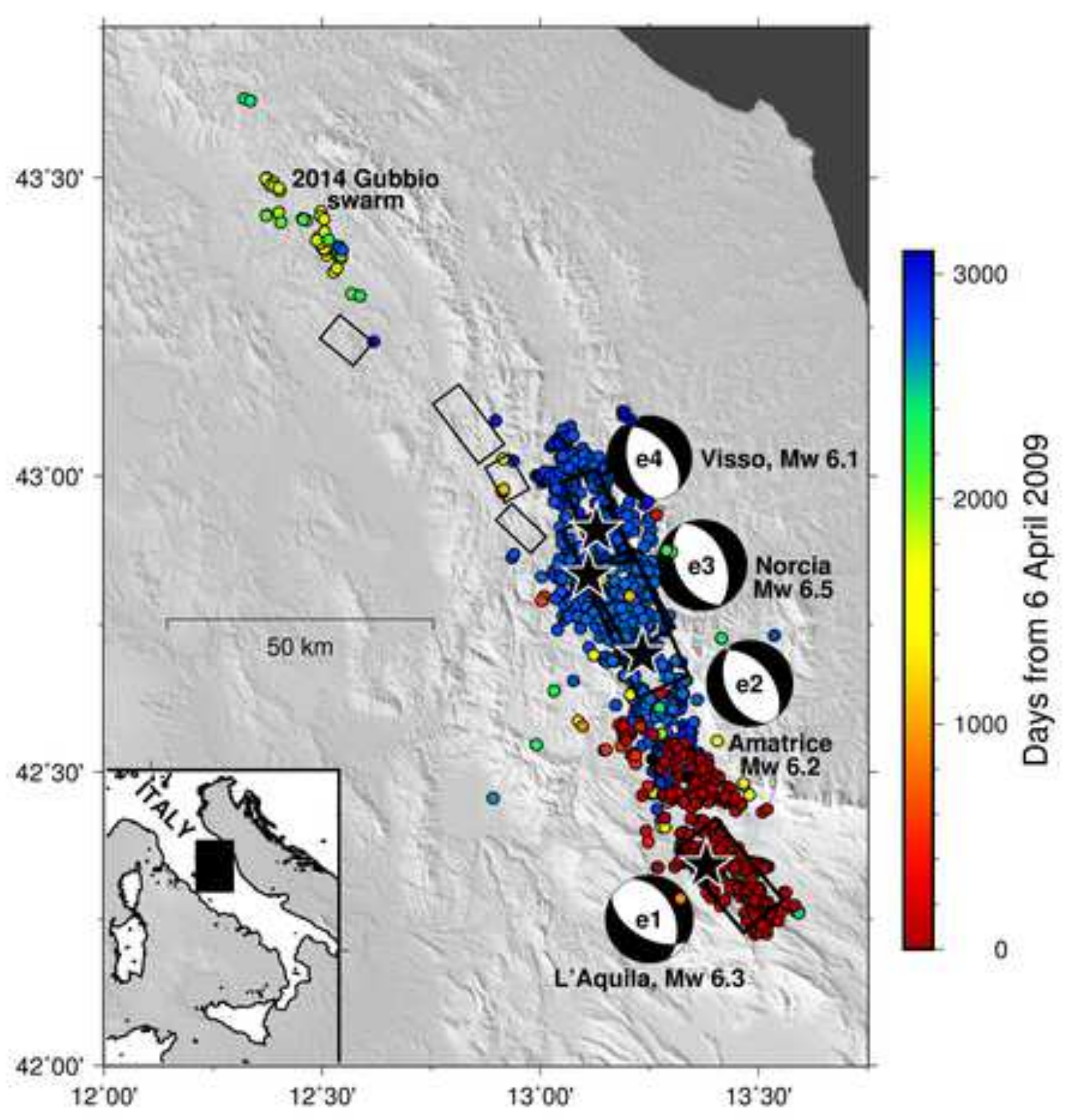



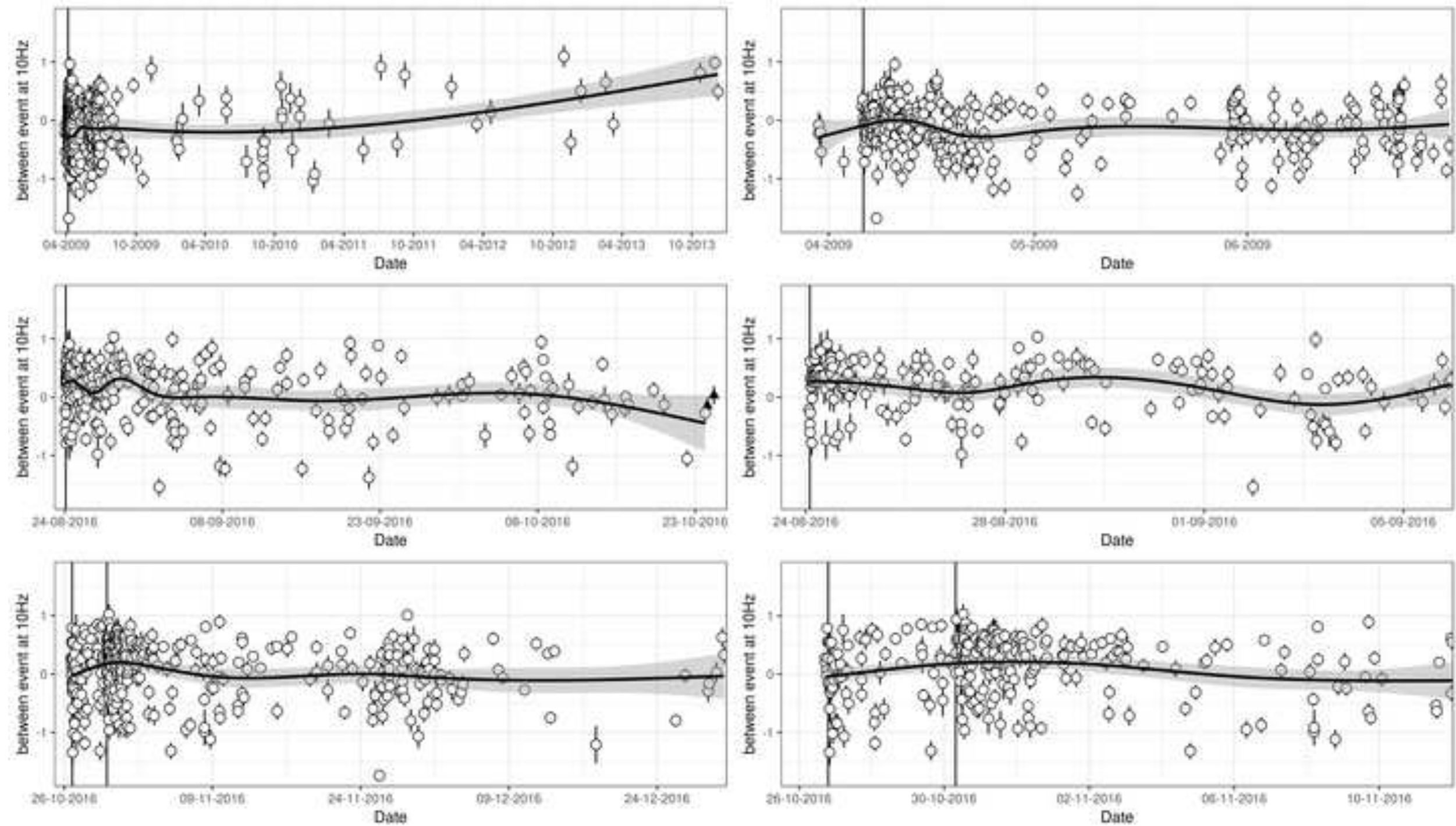


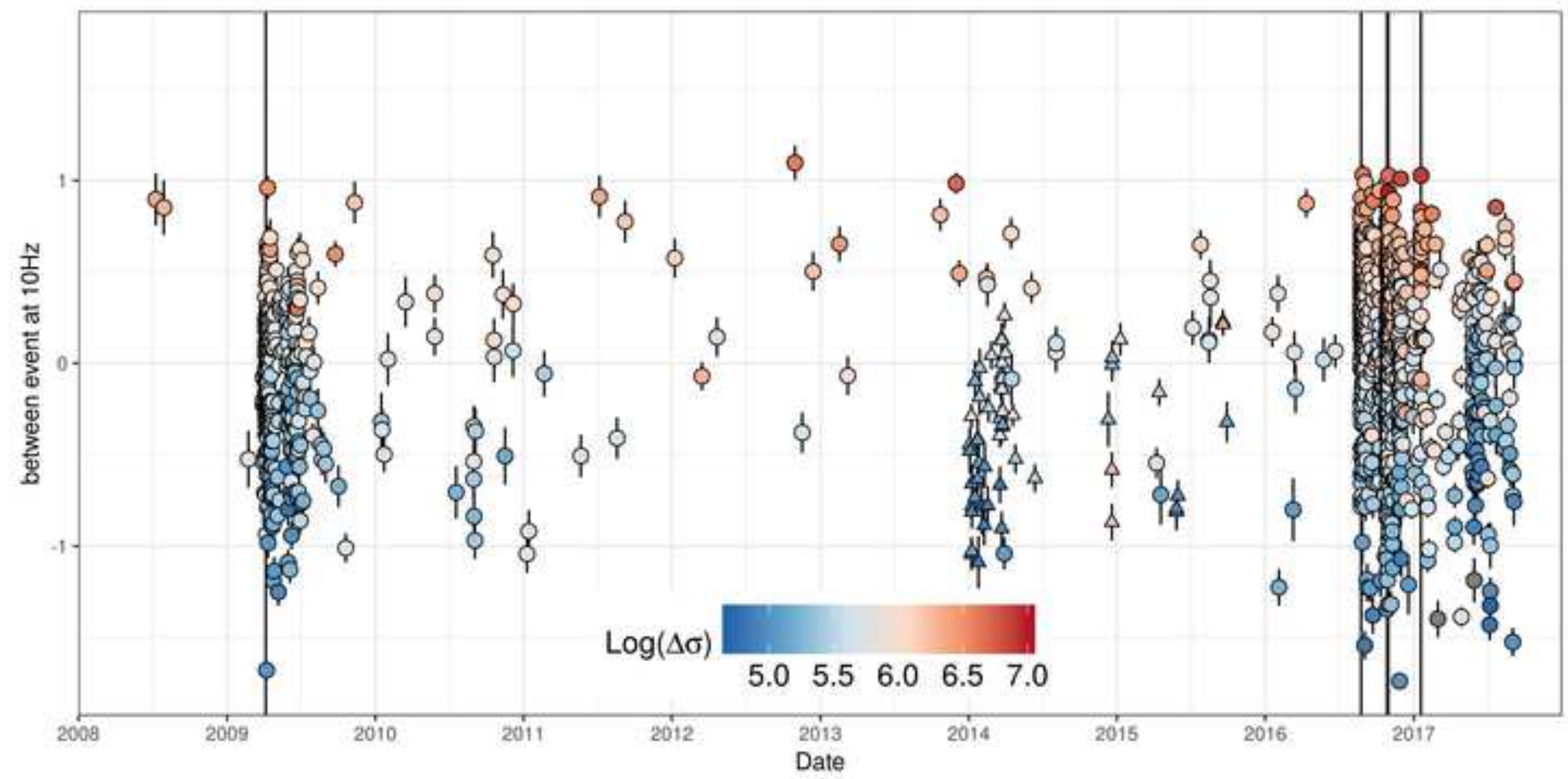




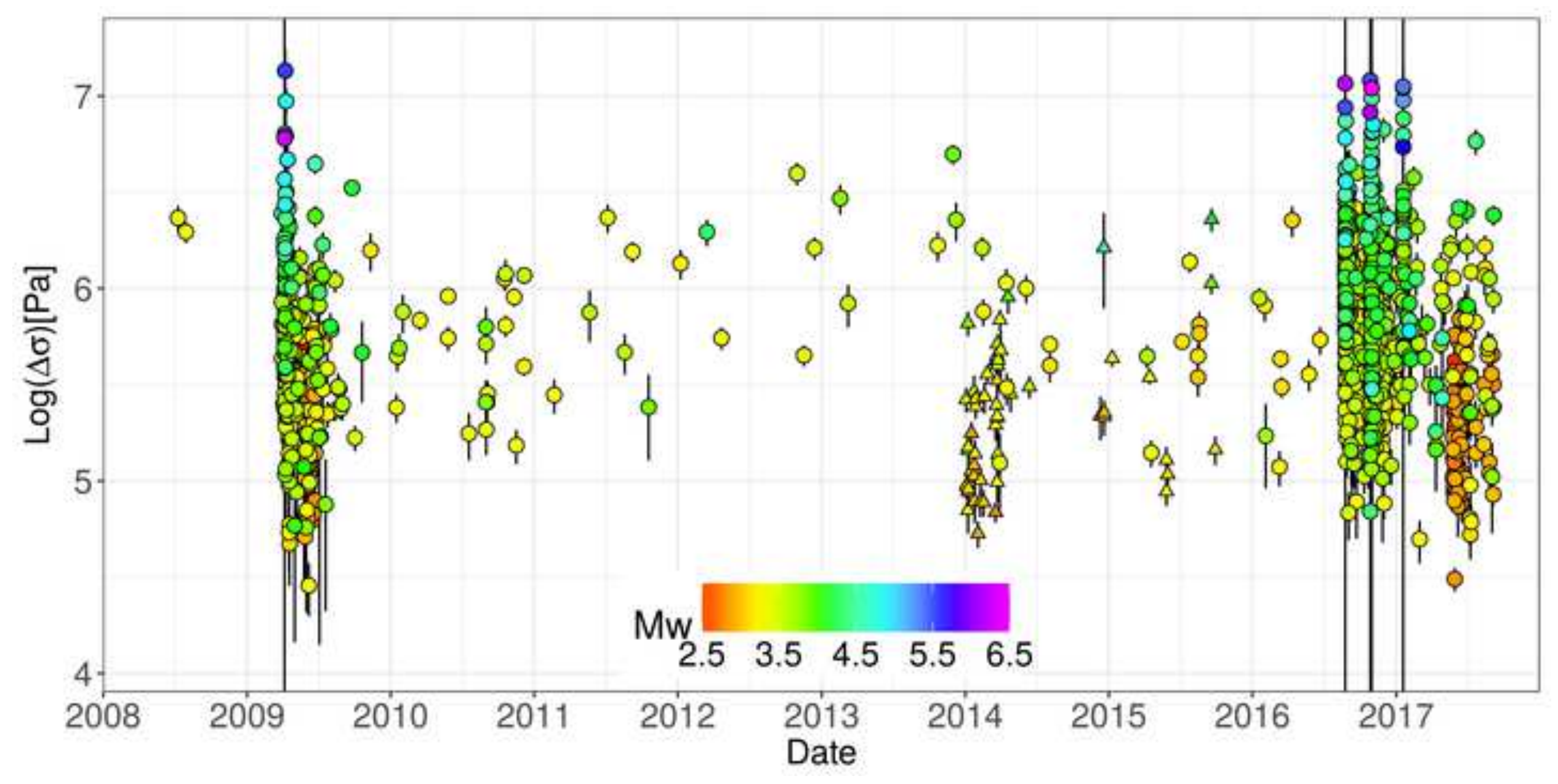




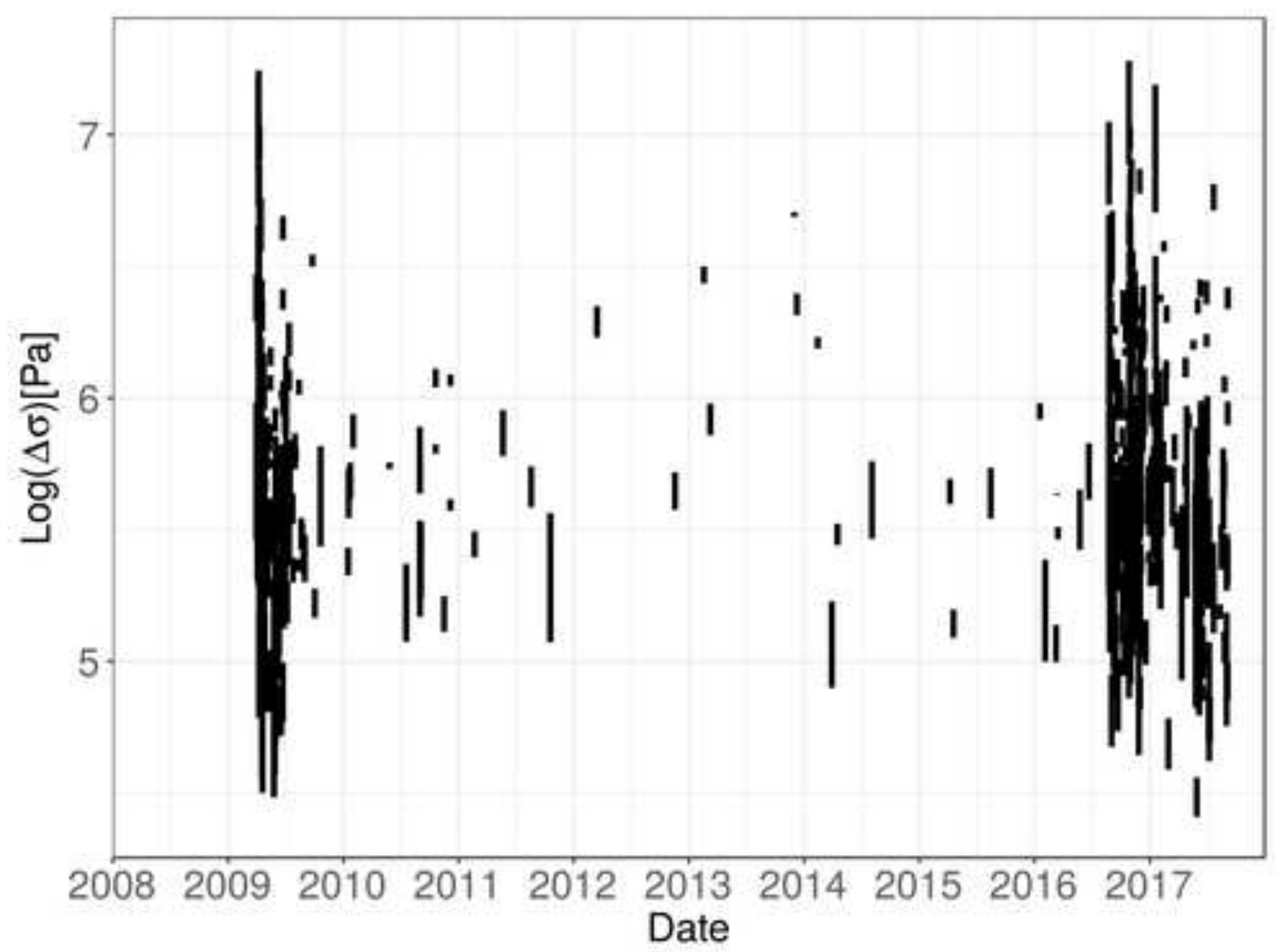




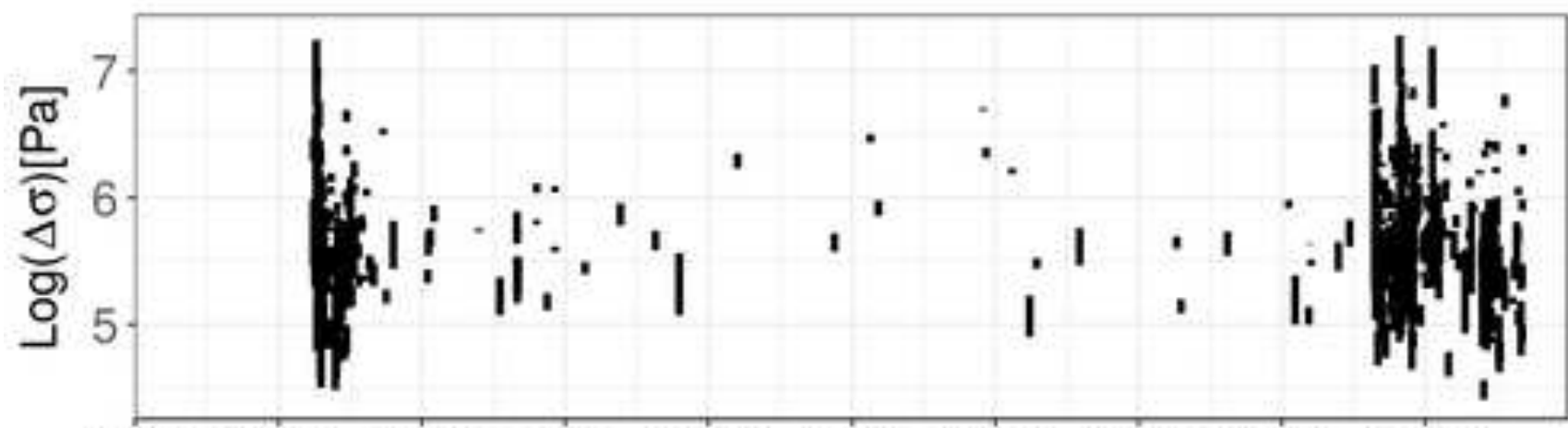

2008200920102011201220132014201520162017
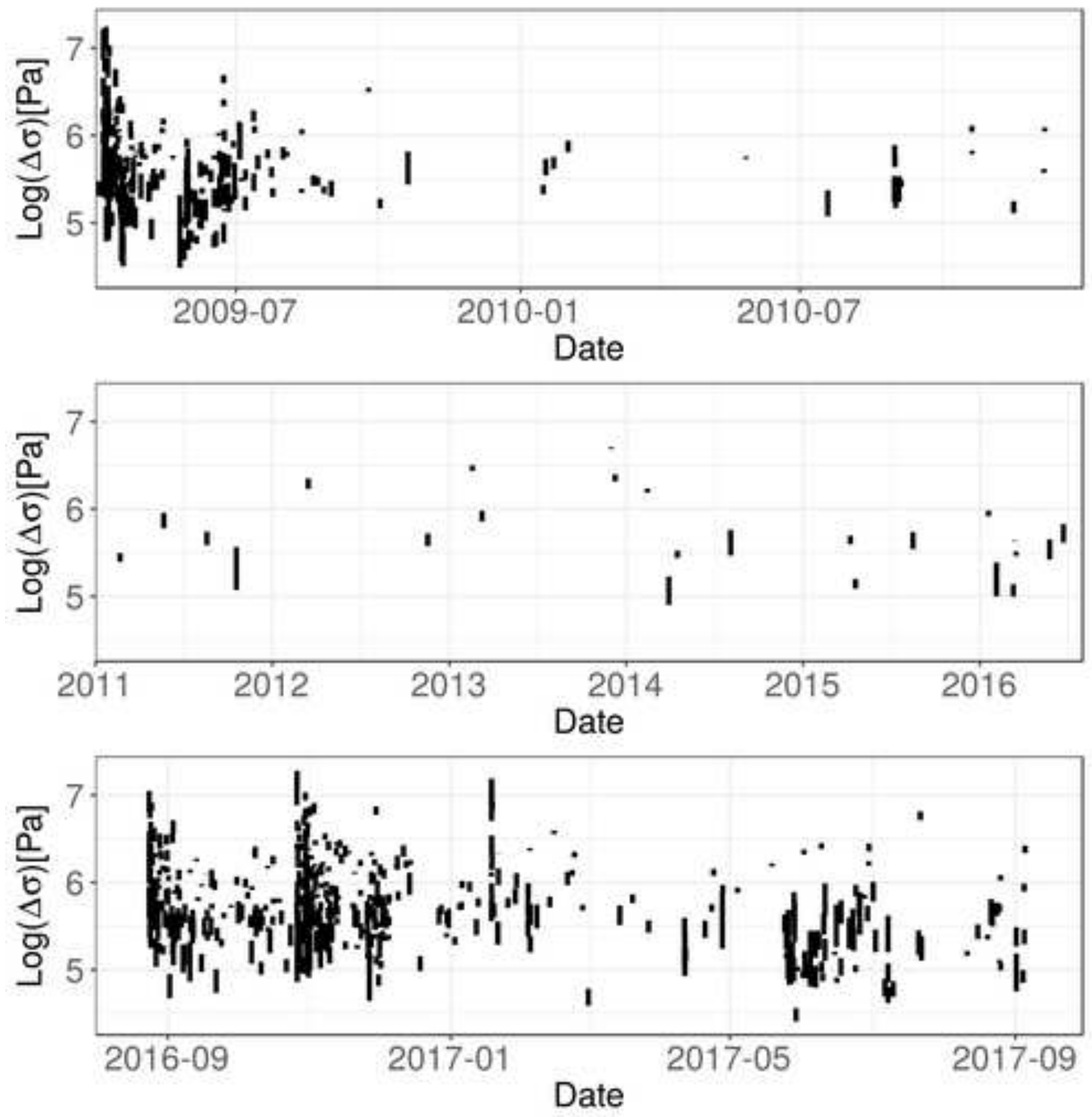

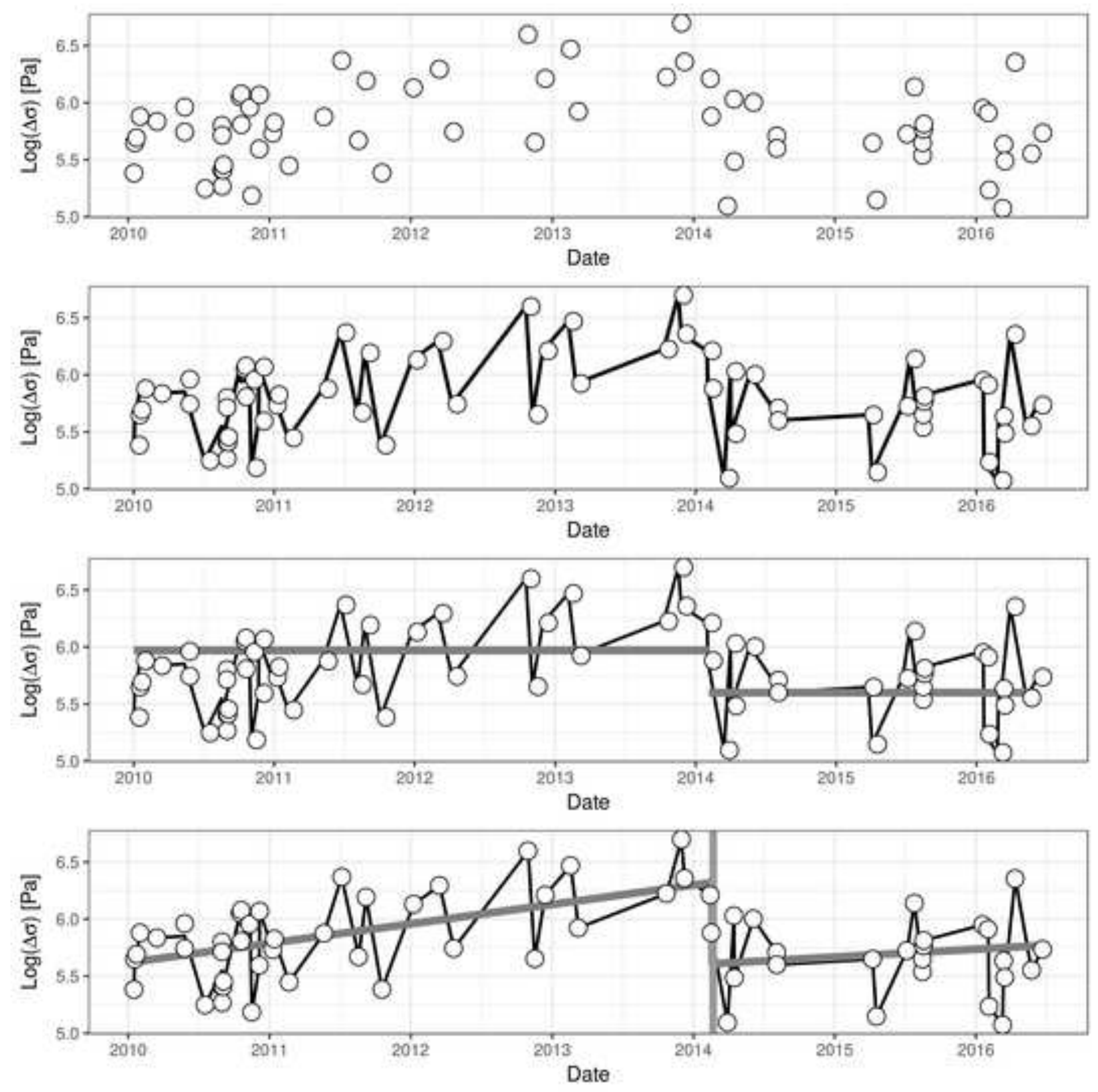